\title{
The processing of staphylococcal biofilm images from Fluorescence and Confocal Microscopy to assess in vitro efficacy of antiseptic molecules
}

\author{
Grzegorz Krasowski ${ }^{1}$, Paweł Migdat ${ }^{2}$, Marta Woroszyło ${ }^{3}$, Karol Fijałkowski ${ }^{3}$, Grzegorz Chodaczek ${ }^{4}$, \\ Joanna Czajkowska ${ }^{5}$, Bartłomiej Dudek ${ }^{6}$, Joanna Nowicka ${ }^{7}$, Monika Oleksy-Wawrzyniak ${ }^{8}$, Bartłomiej \\ Kwiek $^{9}$, Justyna Paleczny ${ }^{8}$, Malwina Brożyna ${ }^{8}$, Adam Junka ${ }^{5,8^{*}}$ \\ ${ }^{1}$ Nutrikon, KCZ Surgical Ward, 47-300 Krapkowice, Poland; g.krasowski@wp.pl (G.K.) \\ 2 Department of Environment Hygiene and Animal Welfare, Wroclaw University of \\ Environmental and Life Sciences, 25 C.K. Norwida st., 51-630 Wroclaw, Poland; \\ pawel.migdal@upwr.pl (P.M.)
}

${ }^{3}$ Department of Microbiology and Biotechnology, Faculty of Biotechnology and Animal Husbandry, West Pomeranian University of Technology in Szczecin, Piastów 45, 70-311 Szczecin, Poland; marta.woroszylo@zut.edu.pl (M.W.); kfijalkowski@zut.edu.pl (K.F.)

4 Bioimaging Laboratory, Łukasiewicz Research Network-PORT Polish Center for Technology Development, 54-066 Wrocław, Poland; grzegorz.chodaczek@port.org.pl (G.CH.)

5 Laboratory of Microbiology, Łukasiewicz Research Network-PORT Polish Center for TechnologyDevelopment, 54-066 Wrocław, Poland; joanna.czajkowska@ port.org.pl (J.Cz.)

6 Department of Microbiology, Institute of Genetics and Microbiology, University of Wrocław, Stanisława Przybyszewskiego 63, 51-148 Wrocław, Poland; bartlomiej.dudek@uwr.edu.pl (B.D.)

${ }^{7}$ Department of Microbiology, Faculty of Medicine, Wroclaw Medical University, 50-368 Wroclaw, Poland; joanna.nowicka@ umed.wroc.pl (J.N.)

8 Department of Pharmaceutical Microbiology and Parasitology, Faculty of Pharmacy Wrocław Medical

University, 50-556 Wrocław, Poland; feliks.junka@gmail.com (A.J.); justyna.paleczny@student.umw.edu.pl (J.P); monika.oleksy@umw.edu.pl (M.O.-W.); malwina.brozyna@student.umw.edu.pl (M.B.)

9 Faculty of Medicine, Lazarski University, $02 \square 662$ Warszawa, Poland; bartlomiej.kwiek@ lazarski.pl (B.K)

corresponding author*: feliks.junka@gmail.com, Department of Pharmaceutical Microbiology and Parasitology of Wroclaw Medical University, Poland 
Abstract: The in vitro efficacy of locally applied antiseptic molecules against staphylococcal biofilm is frequently assessed by a set of standard quantitative and semi-quantitative methods. The development of software for parametric image processing allowed to obtain parametric data also from microscopic images of biofilm dyed with a variety of dyes, especially with propidium iodine and SYTO-9, differentiating dead from live cells. In this work, using confocal/epifluorescent microscopy, we analyzed such major properties of staphylococcal biofilm in vitro as its thickness, cellular density and share of Live/Dead cells within its individual parts. We also scrutinized the impact of sample preparation and antiseptic introduction on the outcome obtained. As a result of our analyses we developed a revelatory method of assessment of the impact of antiseptic agents on staphylococcal biofilm in vitro, in which the microscopic images are processed with the use of ABE formula (Antiseptic's Biofilm Eradication) which implements all the data and phenomena detected and revealed within the course of this study. We tested ABE with regard to polyhexanide, pov idoneiodine and hypochlorous antiseptics and found a high correlation between this parameter and the results obtained by means of traditional techniques. Taking into account the fact that in vitro results of the efficacy of antiseptic agents against staphylococcal biofilm are frequently applied to back up their use in hospitals and ambulatory units, our work should be considered an important tool providing reliable, parametric data with this regard.

Keywords: biofilm, antiseptics, confocal microscopy, fluorescence microscopy, staphylococci, parametric image processing 


\section{Introduction}

The following line of investigation, using primarily confocal/epifluorescence microscopy methodology, was initially thought to be a sub-section of one of the publications as part of an ongoing project concerning an in vitro analysis of the increased efficacy of various antimicrobials against pathogenic biofilms in the rotating magnetic field [1-3]. However, during the course of the investigation, in parallel with our growing understanding of the analyzed matters, an increasing number of methodological and even fundamental questions emerged that had to be answered. What is the structure of biofilm in vitro? How do the preparation and visualization of the sample modify the actual biofilm? What in fact does the operator see using confocal/epifluorescent microscopy? How do antimicrobial molecules affect the structure of biofilm in vitro and what are the properties of such an altered structure? Do these potentially altered properties affect the subsequently applied dyeing process, necessary to perform biofilm visualization? What are the most reliable and optimal ways to change fluorescence signal into useful parametric data? Thus, this seemingly easy-to-perform and to interpret task of microscopic analysis of antimicrobials' impact on biofilm, revealed to us a high number of variables, some of which not-elucidated by other teams.

Therefore, we decided to perform a separate line of investigation, aiming to solve the abovementioned issues and to increase the usability of confocal/epifluorescent microscopy in biofilm studies. Being fully aware of the fact that an excessive number of variables included in the analysis may lead to data overload, resulting in their misinterpretation, we deliberately tailored the initial (broader) research plan, deciding to scrutinize only staphylococcal biofilm and its tolerance/sensitivity to wound antiseptics' molecules. According to a generally accepted definition, biofilms are aggregated communities of microbes, often embedded within a protective matrix, consisting of various molecules (carbohydrate polymers, exocellular DNA, proteins). In the case of wound biofilms, the matrix composition may also involve lysed cells of blood/the immune system and of the wound bed [4]. The biofilm community is considered highly tolerant to antiseptics, antibiotics, antibodies and cellular components of the immune system; not only due to the aforementioned protective matrix, but also due to the high concentration of cells within a relatively small surface and differentiation of the cells' metabolism/growth with regard to their spatial location [5]. Biofilms are considered major causative factors of persistent wounds; treated improperly, they increase the risk of limb amputation or even the patient's 
death [6]. Besides surgical intervention and modern dressings, the present algorithms of biofilm-infected wound treatment recommend the use of antiseptics, which are locallyapplied antimicrobial liquids [7-9]. Noteworthy, the results of in vitro analyses of the impact of various antiseptics against biofilm are frequently used to back up their use in hospitals, care units and in an ambulatory setting. In the in vitro research on the matter, quantitative culturing and colorimetric methods are mostly applied, frequently supported by microscopic images, including images obtained by various types of electron and confocal/epifluorescent microscopy. Presently, the analyses using confocal/epifluorescence microscopy and "Live/Dead" dyeing (showing at the same time viable and compromised cells in the biofilm) to assess the in vitro activity of anti-biofilm compounds are commonly performed and they are a part of the methodological arsenal of a majority of biofilm laboratories. However, for a long time (and still), the results obtained from confocal/epifluorescence microscopy have been mostly presented in the form of the so-called "representative images", being in fact just the back-up for quantitative (e.g. cell culturing) and semi-quantitative (e.g. colorimetric) assays, by means of which the numeric values were provided and subjected to statistical analysis. The emergence of computational software for image processing changed this state diametrically, allowing not only to determine the relationships between biofilm structure and function, but also to extract the parametric data from the collected images [10]. In the case of biofilm studies (and of the impact of various antimicrobials on biofilm), dyeing with propidium iodide (PI) and SYTO-9 molecules is applied the most often, because it allows to differentiate between "Live" (visualized green with SYTO-9) and "Dead" cells (visualized red with PI). The quotations marks are used for the above descriptions of cellular viability deliberately and the reason will be revealed further in the manuscript. The aforementioned dyeing results, observed with the use of microscopic techniques and analyzed with image processing software seem to be a reliable set of techniques applied to determine antimicrobial efficacy. The value of the aforementioned parameter should correlate with an increase in the red fluorescence signal from the PI dye and/or drop in the fluorescence signal from the green dye (SYTO-9). Such changes in fluorescence, recorded by means of image processing software, could be further extracted into numerical values and analyzed with the use of statistical methods. Nevertheless, such a claim is valid only to a certain, general level. Because of the lack of detailed data regarding specific methodological aspects, the phenomena occurring during the introduction of antimicrobial molecules, subsequent preparation of the biofilm sample and further parametric analysis, the outcomes may be very diversified - often even opposing. Such phenomena may be the reason why many research 
teams prefer to use confocal microscopic data in an ornamental way, with the sole purpose to support the "core" parametric results obtained by means of other methods. Therefore, the main goal of the present study was to analyze the above-mentioned phenomena occurring in the range of microscopic and molecular interactions, and to establish the ways for a valid assessment of the impact of antiseptics on biofilm in vitro. Specifically, the discoveries obtained in this manuscript were applied to analyze the efficacy of four commercially available antiseptic products (polyhexanide, povidone-iodine, hypochlorous solution) towards staphylococcal biofilms in vitro.

\section{Results and Discussion}

The first of just a few axioms which should be established at this point of the discussion is that staphylococcal in vitro biofilm observed by means of confocal/epifluorescent microscopy is not the actual biofilm but an image of it; in other words, the properties of the actual biofilm are to some (and major) extent modified by the procedures of sample preparation (rinsing, dyeing, fixing), the microscope usefulness (magnification, resolution) and the operator's skills (ability to capture and extract appropriate data). When the biofilm image is taken, a whole new class of modifiers occurs, related with the operator's ability to identify and to interpret the observed structures, processes and phenomena; and with the operator's ability to change them into correct parametrical values using computational software for image processing. One of the major discoveries of this study is the fact that the procedures leading to biofilm (sample) preparation alter its structure significantly and have an impact on the outcomes (images) obtained. Because the explanation of the main alterations exerted by preparative procedures on biofilm structure without prior defining the main properties of the biofilm structure would be a methodological flaw (ignotum per ignotum), at this point the major characteristics of in vitro staphylococcal biofilm is presented, while the data on the specific influence of sample preparation and image computing is developed in subsequent sections. Biofilm (in general) is considered to be an adhered, three-dimensional, spatial structure consisting of microbial cells embedded within an extracellular matrix, displaying high tolerance to environmental factors (with regard to medical biofilms, these factors are usually antimicrobials and the immune system) [11]. The metabolic differentiation within biofilm parts is also frequently mentioned [12-14]. Such a definition is derived from the early observations of dental plaque biofilms [15] and is repeated frequently in the introductory parts of scientific manuscripts. The above definition matches, in its entirety, only specific types of biofilms, while it does not match such thoroughly investigated microbial structures as for 
example floating (non-adhered) biocellulose pellicles (mats) of Komagataeibacter xylinus or Escherichia coli $[16,17]$; it also does not entirely match biofilms whose protective matrix consists not of self-produced extracellular substances but, to a major extent, of lysed cellular components of the host macro-organism [18]. Therefore, especially in the context of medical biofilms, the more utilitarian definition is frequently accepted, i.e. biofilms are these microbial, multi-cellular structures which display elevated tolerance to the environmental factors. Such a definition of biofilm is frequently opposed to the so-called "planktonic cells", defined as free-swimming microbial cells, whose tolerance to antimicrobials/the immune system is the sole resultant of their intrinsic properties (cell wall structure, secretion of enzymes or toxins, etc.) [19]. Even though it is true that staphylococcal biofilm forms (in in vitro conditions) an adhered [20], multi-cellular [21], spatially dense [22] structure of highly elevated tolerance to antimicrobials $[3,23,24]$, the claim that its extracellular matrix is a robust one (or that staphylococcal cells are embedded within it) is a significant overinterpretation. As shown by Williams et al. [25], the staphylococcal cells are rather interstabilized by fimbriae-like adhesins and covered with polymeric substances from the lysed cells [26], including extra-cellular DNA. Staphylococcal biofilm in vitro is frequently visualized (especially by means of Scanning Electron Microscopy) as a flat, lawn-like structure (of a relatively even height). This common generalization, committed also by the authors of this manuscript in their earlier works, is related to the fact that SEM allows to observe the biofilm mostly from the aerial (top plane) perspective. Moreover, the preparation of the samples for SEM analysis requires numerous introductions and aspirations of liquids (glutaric aldehyde, water, ethanol), which increases the probability of removal of most protruding parts of the biofilm from the experimental setting. But in fact, as shown in Figure 1A., staphylococcal biofilm resembles a hilly landscape (characteristic mushroom-like structures pointed out by Williams et al. [25]) more than a lawn. Moreover, staphylococcal biofilm in vitro, if cultured in a standard microplate setting (e.g. $24 \mathrm{~h}$ of culturing, inoculum of $10^{5} \mathrm{cfu} / \mathrm{mL}$ ) is of a highly confluent character, i.e. biofilm-forming cells cover basically the whole surface of the plate's wells [Figure 1B]. Therefore, looking at a picture such as Figure $1 \mathbf{B}$, the observant should realize that the thickness observed in this structure is lower in part " 1 " than in parts " 2 " and " 3 " (in turn, the differences in thickness between " 2 " and " 3 " are of a less univocal character, as will be explained in the subsequent parts of the manuscript). 


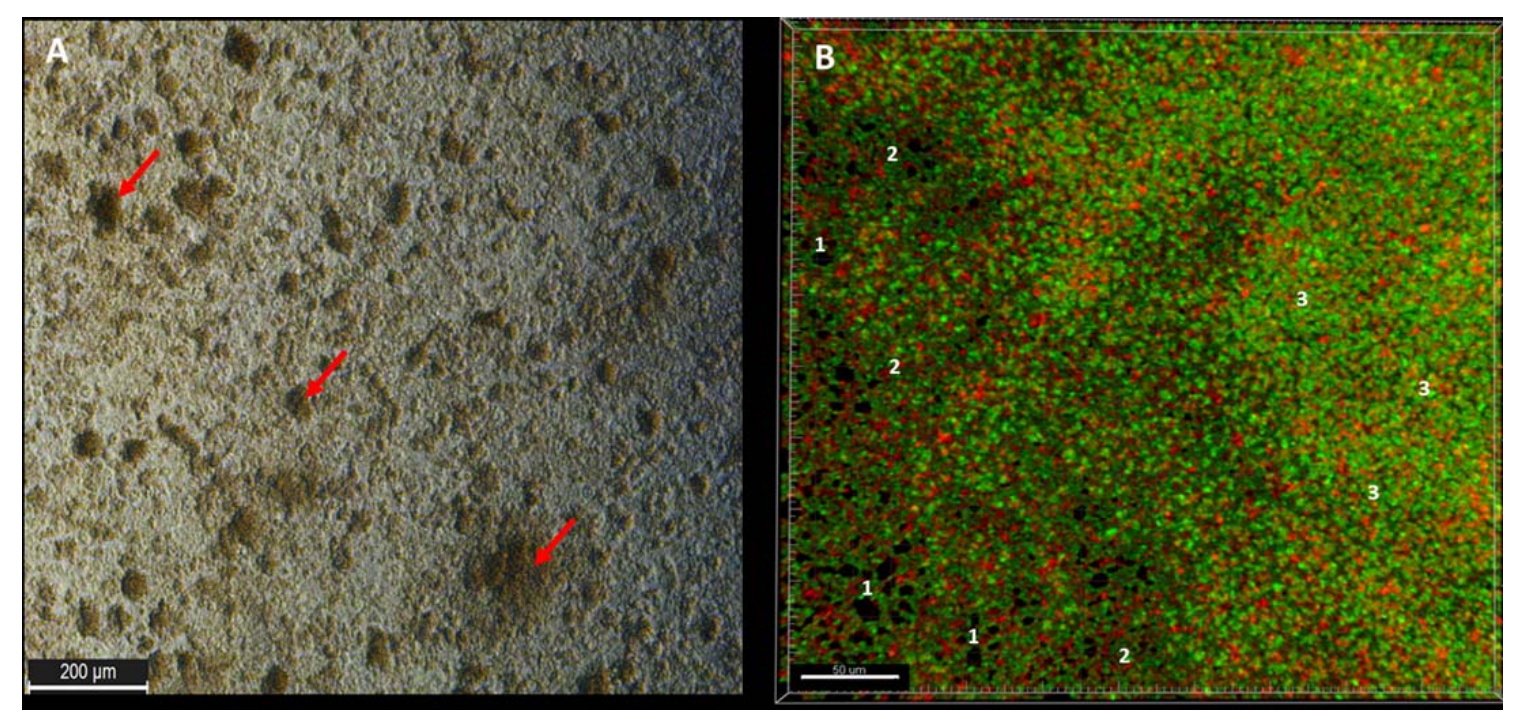

Fig.1. A - Young, 12h staphylococcal ATCC 6538 biofilm grown in a microplate (24-well) seen in an optical microscope (aerial perspective) without any prior preparative procedures; red arrows indicate areas of higher cellular density (mushroom-like structures); B - aerial perspective of L/D-dyed, 24h biofilm of the same strain. The "1s" show areas non-covered with cells (holes); the $2 \mathrm{~s}$ " show areas of lower cellular density (of higher intensity of green color) than areas designated with " $3 \mathrm{~s}$ " (of lower density of green color). Red shapes are cells of decreased viability (with a compromised cell wall) or dead; while green shapes are viable cells (of non-compromised cell wall). Picture A, inverted microscope DMIL LED, magn. 10x; Picture B, confocal microscope SP8, magn. 40x.

The application of confocal microscopy allows to visualize biofilm not only from the aerial perspective, but also along the Z-axis, providing a more detailed insight into the distribution of staphylococcal cells (and their state) within the biofilm structure. The data presented in Figure 2 additionally back up the data from Figure 1A, concerning uneven, hill-like shape of in vitro staphylococcal biofilm (which includes regions of different thickness, areas noncovered with cells ("holes") and areas of different cell density). The standard, 24h lasting culture in a 24 -well plate of 10 biofilms of different staphylococcal strains (including two reference ones) resulted in a high level of confluency (the percentage of the culture vessel surface area that appears covered by a layer of cells when observed by a microscope), of average $93.6 \pm 5.5 \%$ (Table $1 S$ ). 


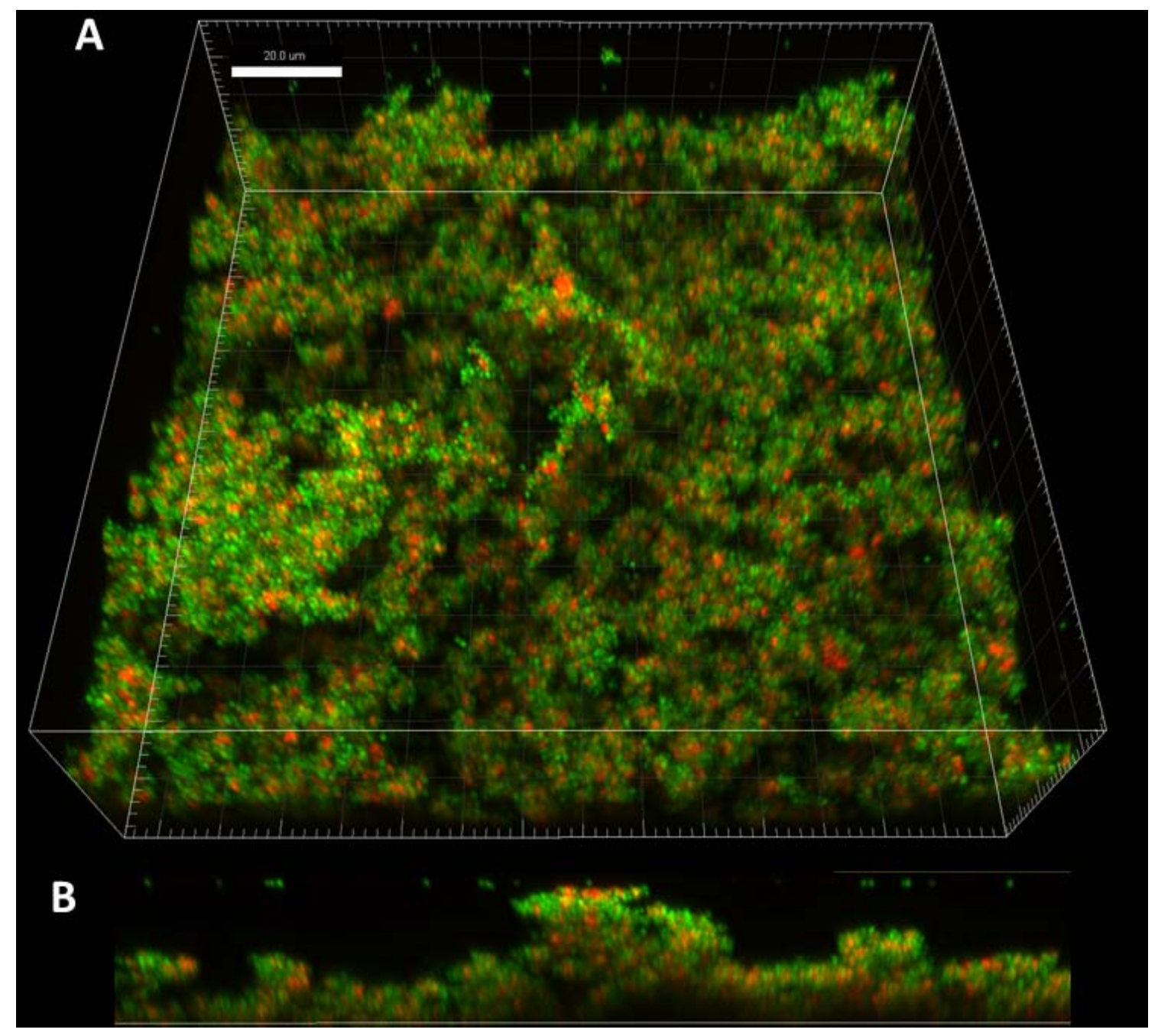

Fig.2. The $Z$ axis image stack visualizing ATCC 6538 staphylococcal biofilm from the side aerial perspective (A). Part $\mathbf{B}$ of the figure shows the vertical cross-section through the threedimensional biofilm structure. The regions of various height and density are explicitly visible. Microscope Cell Observer, magnification 40x.

The generally accepted statement concerning cells in biofilms is that cells located in the top (T) layer of biofilm require more access to oxygen and to nutrients than the cells located in the bottom (B) parts of the biofilm [27]. Therefore, the latter cells are characterized by a lower metabolic activity and by an increased tolerance to these antimicrobials which act through interference with such energy-requiring processes as protein translation. Noteworthy, the latest discoveries indicate that the metabolic differentiation and cellular access to nutrients within biofilm is not simply the effect of the cells' stratification but is regulated by highly complex pathways of inter-cellular feedback signaling [28]. Nevertheless, the abovementioned differentiation remains undisputable. We hypothesized that such a differentiation may also be detected by means of L/D dyeing, i.e. we assumed that the share of dead/wall 
compromised cells would be higher in the bottom B parts of the biofilm than that of the cells located in the T parts of the biofilm. Figure 3 presents the three typical vertical cross-sections of staphylococcal biofilm structure. All of them share two common denominators. The first one is that the majority of dead/cell wall compromised cells are located at the bottom of the biofilm, while the differences include the share of dead/cell wall compromised cells in the middle (M) and the top (T) parts of the biofilm. In the first pattern, the number of dead/cell wall compromised cells is very scant (these parts of biofilm consist primary of viable/cell wall non-compromised cells) in the $\mathrm{M}$ and $\mathrm{T}$ parts. In the second pattern, the share of $\mathrm{dead} / \mathrm{cell}$ wall compromised cells is higher in the $\mathrm{M}$ and $\mathrm{T}$ parts than in the first pattern; the dead/cell wall compromised cells are located randomly across the structure. Contrary, in the third pattern, not only the B but also the $\mathrm{T}$ part of the biofilm consists mostly of dead/cell wall compromised cells and these two distinctive layers are divided by the M part of the biofilm consisting mostly of viable/cell wall non-compromised cells. Fifty percent of the strains analyzed in this research formed biofilm presented in Fig.3 A, in $30 \%$ of them the cell distribution took the form presented in Fig.3B, while 20\% formed a structure presented in

Fig.3C.

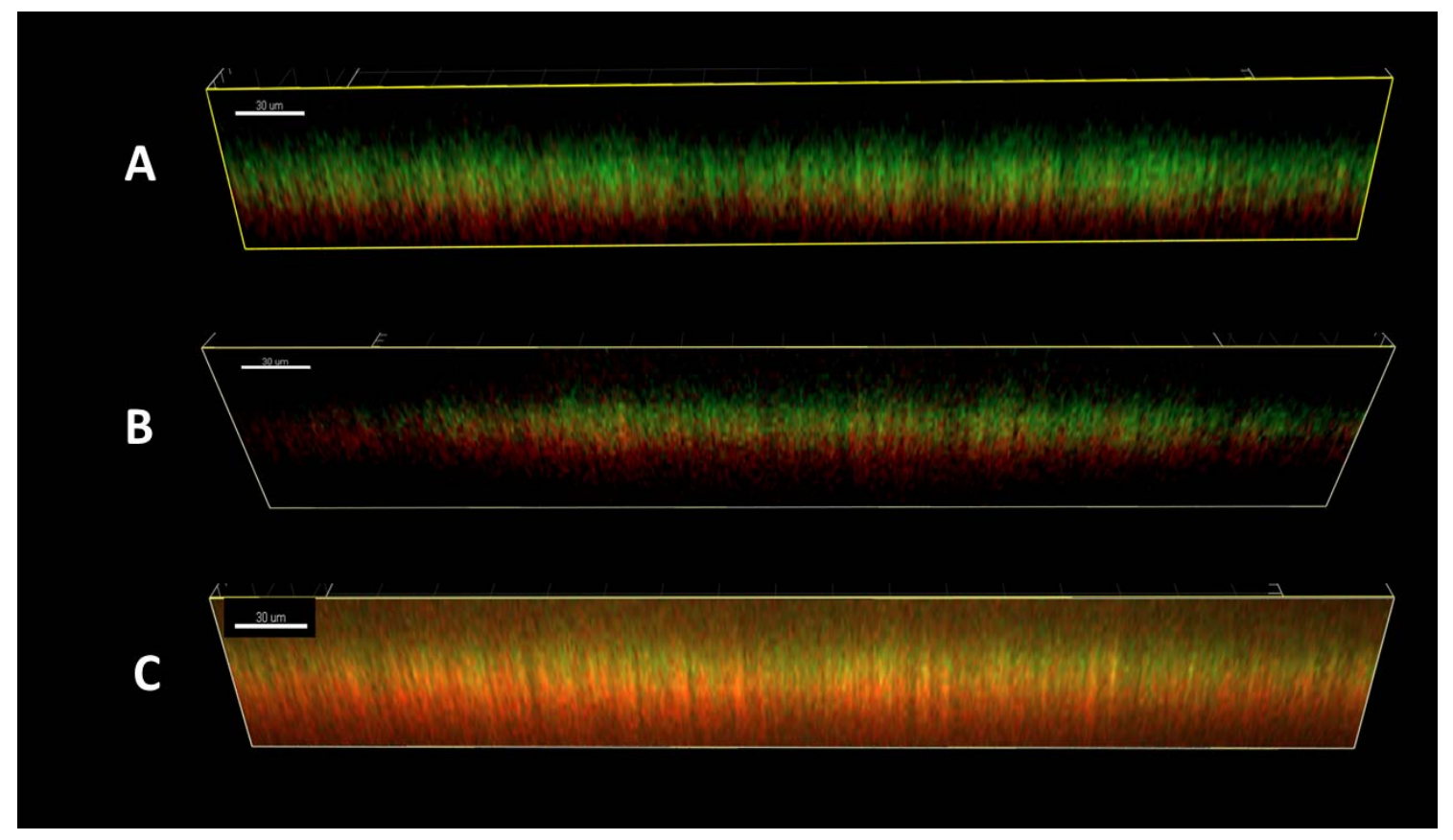

Fig.3. Three types (A,B,C) of distribution of dead/cell wall compromised cells vs. viable/cell wall non-compromised cells in staphylococcal biofilm in vitro; the vertical cross-section through the biofilm structure. A - strain ATCC 6538; B - strain S1, C -ATCC 33591. Scale bar is $30 \mu \mathrm{m}$. Microscope SP8, magn.40x. 
Noteworthy, the different cell distribution types presented in Figure $\mathbf{3}$ may occur simultaneously within a single culture plate well (Figure 1S). Such staphylococcal biofilm heterogeneity, manifested in the various distribution patterns of fully viable vs. compromised cells may be of high importance with regard to the activity displayed by these antiseptics which act through disintegration of microbial cell wall (for example polyhexamethylene biguanidine [29]). One may expect that their effectiveness may differ depending on the type of biofilm they will be used against, i.e. whether the antiseptic molecules will have an initial contact with the heavily damaged cells of such biofilm as presented in Figure 3C or with mostly non-compromised cells forming biofilm structure presented in Figure 3A. In fact, the normative methods of assessment of antiseptic activity [30] imply the use of an "organic burden" (bovine serum albumin and/or blood cells) to analyze the impact of this load on antiseptic molecules activity, which is mostly negative (the effectiveness drops). One may hypothesize that the $\mathrm{T}$ part of biofilm presented in Figure 3C may act in a similar manner as organic load applied in normative methods, because it contains a high share of cell debris (protein, eDNA, phospholipids, etc.). The analysis performed by means of confocal microscopy revealed another common denominator of all analyzed biofilms. Their cellular density (measured by detection of incorporated dyes' fluorescence intensity level) was the highest in their M part, and lower in parts B and T (Figure 4). This observation was recorded for 100\% $(n=10)$ biofilms formed by analyzed strains (Table 2S). 


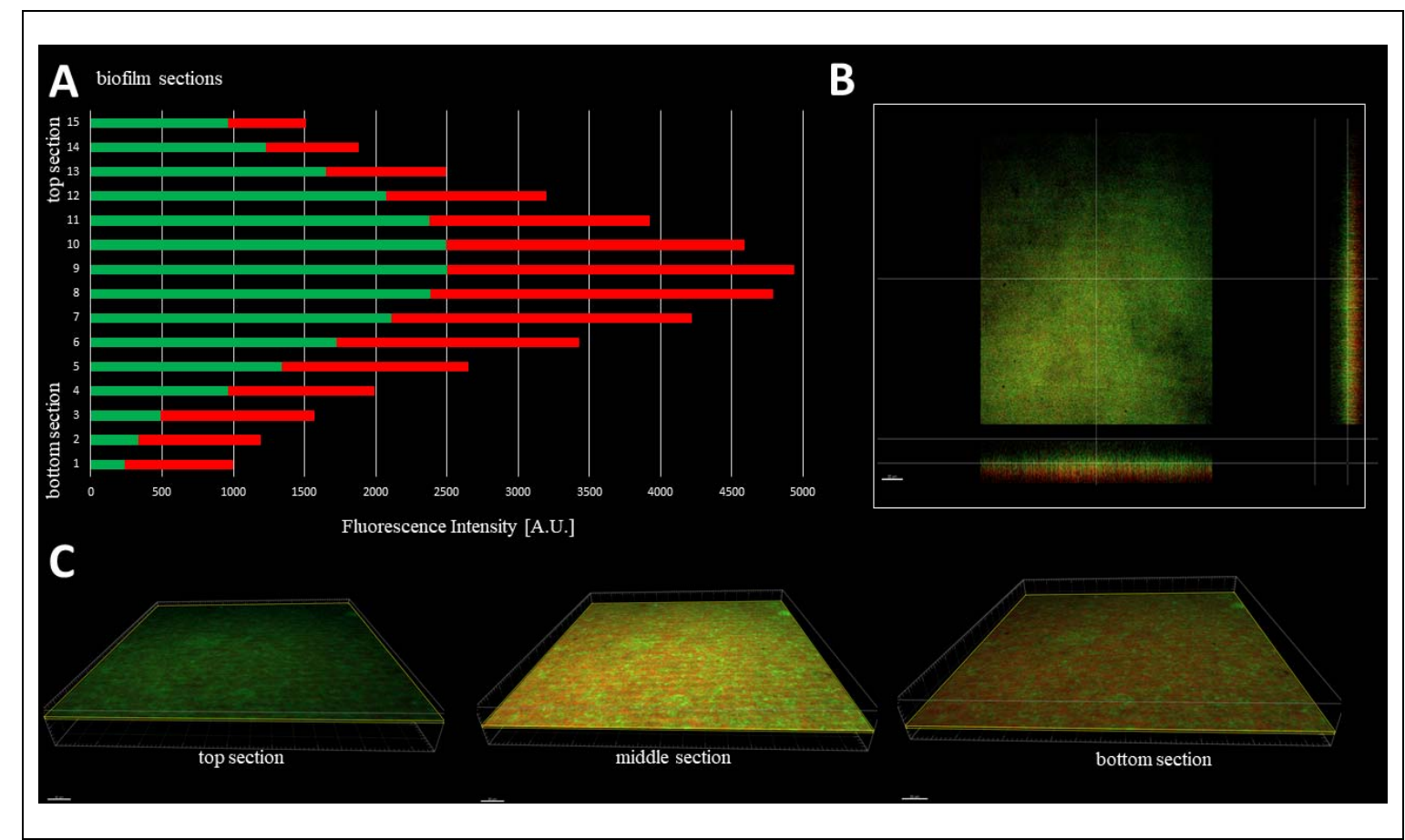

Fig.4. Typical distribution of cellular density through the biofilm (ATCC 6538 strain) from its top to the bottom section [A, B] and the growing share of dead/cell wall compromised cells in the deeper parts of biofilm $[\mathrm{A}, \mathrm{C}]$. Thickness of every section was $2.16 \mu \mathrm{m}$. Red and green color in [A] represents Fluorescence Intensity of propidium iodide or SYTO-9, respectively; microscope SP8, magn. 40x. Scale bar is $50 \mu \mathrm{m}$.

The other question that should be addressed concerns the areas described as "the holes", pointed explicitly as "1s" in Figure 1, seen also in Figure 2b (black areas). With regard to the matter discussed (estimation of antiseptics' effectiveness), identification of these areas is of paramount significance. The antimicrobial activity of most antiseptics relies on destruction of bacterial cell walls (and biofilm matrix) and one may hypothesize that the result of such activity may be empty spaces in the biofilm structure, contributing to the drop in confluency level. Such a drop in confluency is commonly observed in eukaryotic cell cultures in vitro, after the introduction of molecules displaying high cytotoxic potential [31]. Noteworthy, the occurrence of holes (black, non-fluorescent areas) in biofilm, would also suggest that the specific antiseptic was able to penetrate through the whole biofilm structure (from part $\mathrm{T}$ to $\mathrm{B}$ along the Z-axis and to kill biofilm-forming cells). The high tolerance of the deeper parts of biofilms to antibiotics and the immune system components is one of the main clinicallyrecognized challenges impeding effective biofilm's eradication [32]. Therefore, these antiseptics whose activity correlates with the formation of new holes within biofilms should be considered the most effective ones. As already mentioned, the standard in vitro culture of staphylococci scrutinized in this research correlated with the formation of biofilm with an 
almost full confluency (average above 90\%). The lowest confluency (81.7\% ) among the tested strains was displayed by the S1 strain. For the biofilm of this strain, an analysis aiming to evaluate the character of black, non-fluorescent areas was performed using L/D dyeing and the highest-to-achieve (x100) magnification (Figure 5, lower part of panel).
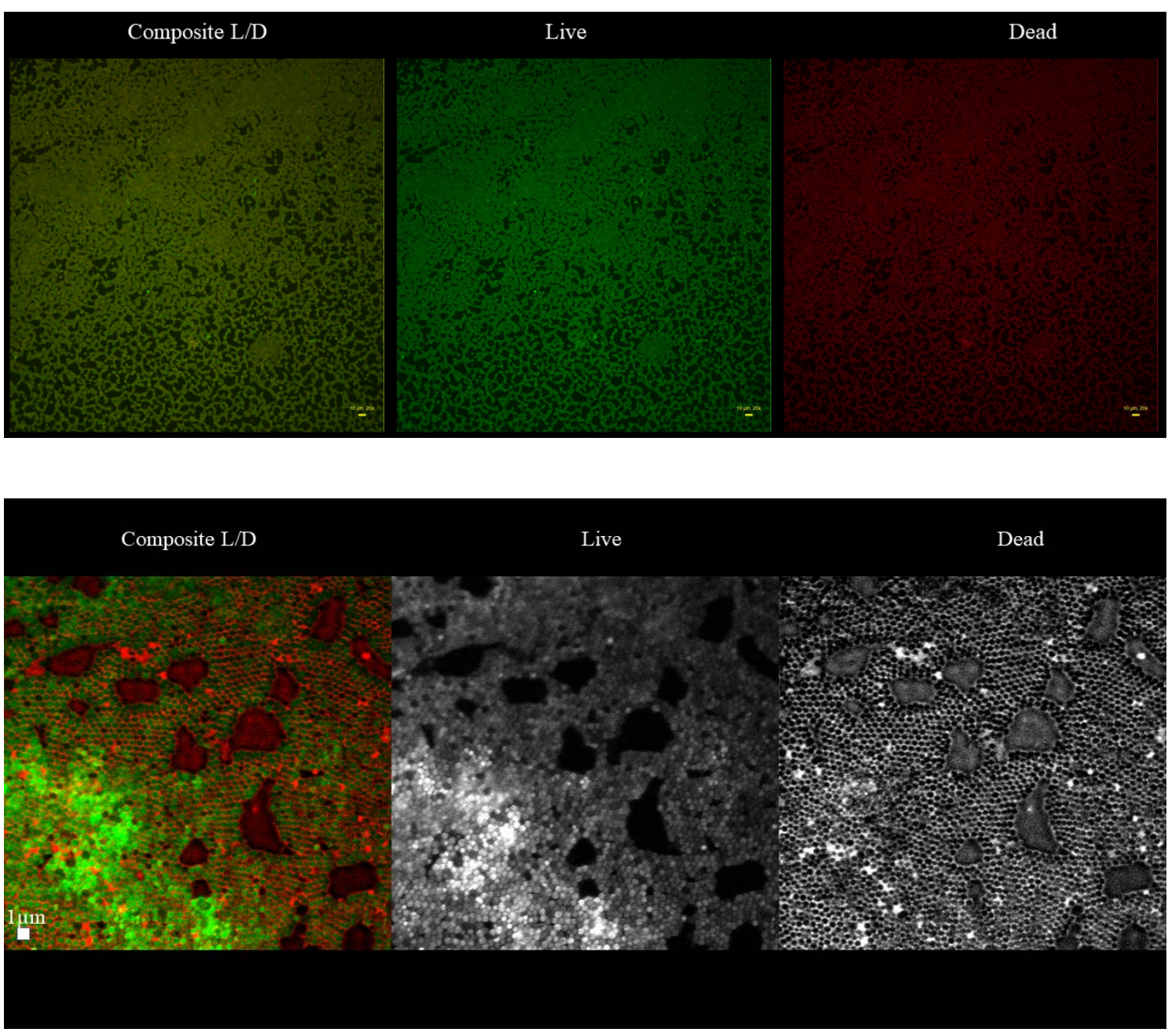

Figure 5. The presence of black non-fluorescent areas ("holes") in the biofilm of the S1 strain. The upper part of the figure shows holes in the area magnified 20x (the upper panel consists of a composite image (L/D) and split channels ("live" - middle picture; "dead" right picture). The bar size is $20 \mu \mathrm{m}$. The "holes" are not- fluorescent in any channel in this magnification (seen as black areas). In the 100x magnification (lower panel), "holes" take forms of non-fluorescent or red-fluorescent areas. Bar size is $1 \mu \mathrm{m}$. For higher visibility, in the lower panel, the dye distribution (color fluorescence) was presented in the grey (from white to black) spectrum of colors. Upper panel: microscope LumaScope 600, magn.20x; Lower panel: Microscope Cell Observer, magn.100x.

Therefore, the main conclusion from this investigation line is that "holes" consist of area noncovered with cells or covered with the cellular debris (the distribution of PI is uniform, there are no signs of remaining cellular, oval shapes, Figure 5). The analysis of the properties of 
staphylococcal biofilm in vitro should also include another factor, namely the height (thickness) of the biofilm, understood as the number of subsequent cells along the Z-axis. The average diameter of a single staphylococcal cell is considered to be around $1 \mu \mathrm{m}$ [33]. The same value was recorded experimentally in this study [Figure 2S] by means of SEM. The parameter of thickness is crucial with regard to the application of antiseptics against biofilm, because it may be hypothesized that the application of cell wall-destructing antiseptics should lead to the removal of cells and to a decrease in biofilm thickness. This assumption is valid not only because of the aforementioned activity mechanism of these antiseptics, but also because of the rheological phenomena occurring during antiseptics' introduction, removal and subsequent laboratory stages of dye introduction and microplate well rinsing. At this point of the discussion, the already proven (Figure 1 and Figure 2) characteristics of staphylococcal biofilm in vitro should be reminded: the staphylococcal biofilm in vitro is of hill-like character (which translates into different thickness recorded in the different areas of the microplate well). There is also another variable which should be mentioned: the un-dyed staphylococcal biofilm can be seen in the bottom of the microplate well with the naked eye (Figure 3S). The smallest object that a normal eye with regular vision and unaided by any other tool can see is considered to be 0.1 millimeter [34]. It means that at least some areas of a cultured biofilm structure are of thickness which is beyond the scanning ability of the most advanced confocal microscopes. The issues with other methods which could potentially assess the actual biofilm thickness are their low usability for biological samples (as in the case of a profilometer) or their too high sensitivity. As an example, in the case of Atomic Force Microscopy, able to detect and to visualize even such small objects as staphylococcal adhesins [35], the mapping of the whole surface of biofilm-covered microplate [approx. $254 \mathrm{~mm}^{2}$ ], would be not only too time-consuming, but also it would generate an amount of data nearly impossible to process. Bearing in mind the above-mentioned disadvantages of Confocal Microscopy, we have performed the analyses of biofilm thickness measured from the point where the fluorescence level starts to be detectable (the $\mathrm{T}$ part of biofilm) to the point where the fluorescence level was equal to the threshold (value of fluorescence recorded for an un-dyed sample) level, understood as the area where biofilm ends and polystyrene surface of the microplate begins. The results of the analyses performed for all 10 staphylococcal biofilms are presented in Figure 6. As can be observed, the measured thickness of staphylococcal biofilms differs not only between particular strains, showing explicitly the importance of intra-species variability [36], but also within a single sample (well of a 24-well microplate), repeatedly showing the 
hill-like structure of the analyzed staphylococcal community. This thickness differentiation is meaningful, taking into consideration the activity of antiseptics against biofilm. We are presently unable to analyze and predict all the phenomena taking place after the introduction of antiseptic molecules to the biofilm-containing microplate well. Firstly, the process of antiseptic's pouring in initiates a number of rheological and dynamic processes resulting in (random from our perspective) breaking off of biofilm parts. Secondly, the level of biofilm eradication depends on the specific antiseptic agent's mode of action, its ability to penetrate through the matrix and on the cells' susceptibility. Nevertheless, one may hypothesize that the thinner the biofilm in a particular area, the higher probability that the activity of an antiseptic will result in higher biofilm removal and formation of holes.

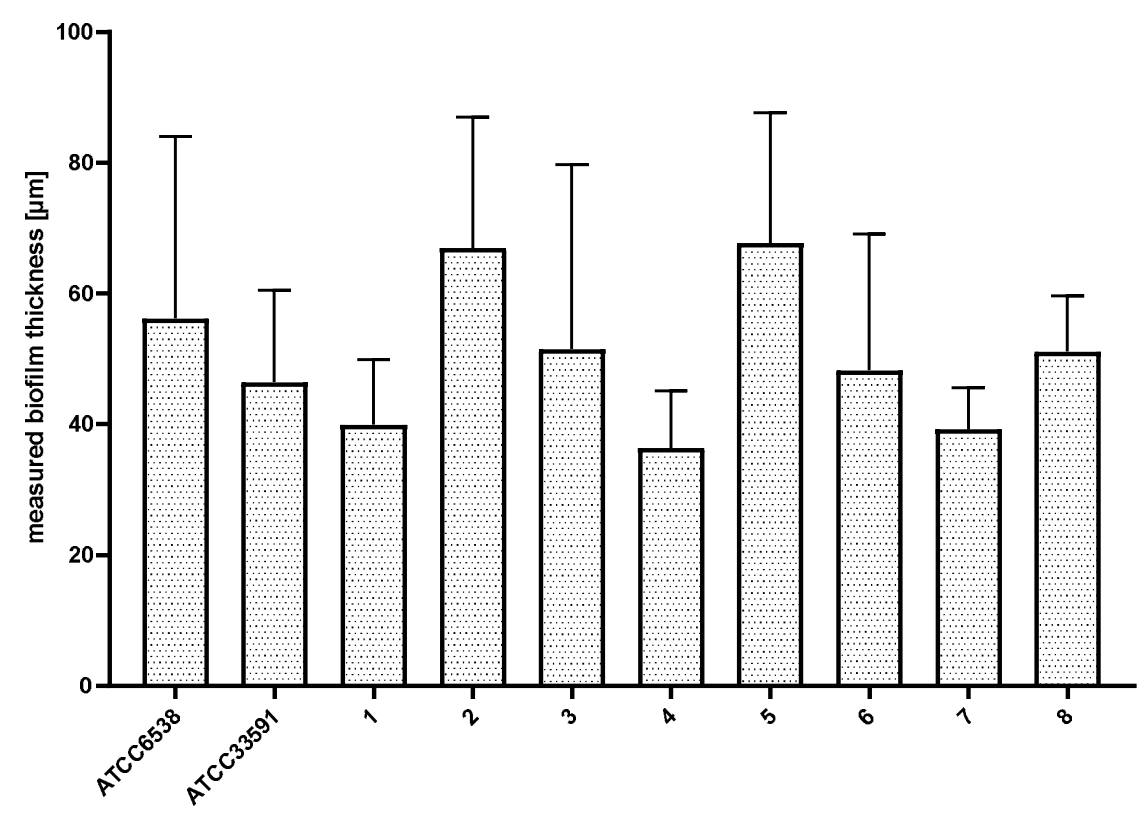

Figure 6. Measured thickness of staphylococcal biofilms $(\mathrm{n}=10)$ in vitro.

Because, as shown in Figure 6, the staphylococcal biofilm formed by a particular strain consists of regions of various thickness ("hill-like landscape"), one may expect that the activity of an antiseptic against confluent biofilm would result in the formation of holes in areas where the biofilm was relatively thin and in a decrease in biofilm's thickness in areas where the biofilm (before the introduction of the antiseptic) was relatively thick (such decrease in thickness should correlate with a decrease in fluorescence level). Noteworthy, there is no direct correlation between biofilm thickness and intensity of measured 
fluorescence, which means that biofilm structure contains also such thin areas of whose fluorescence level is higher compared to the areas of higher thickness [Table 1].

\begin{tabular}{|c|c|c|c|c|c|c|}
\hline $\begin{array}{c}\text { thickness } \\
{[\mu \mathrm{m}]}\end{array}$ & 60.48 & 34.56 & 30.24 & 69.12 & 103.68 & 38.88 \\
\hline $\begin{array}{c}\text { fluorescence } \\
{[\text { SYTO-9] }} \\
\text { A.U. }\end{array}$ & 104.7 & 80.5 & 79.2 & 147.6 & 178.6 & 64.9 \\
\hline
\end{tabular}

Table.1. Lack of correlation between measured thickness of biofilm and the corresponding fluorescence level.

However obvious this constatation may seem, it is associated with the important statement that various regions of biofilm display various cellular density [Figure 7]. Following this thought, these thinner parts of biofilm, which display high cellular density, may be harder to eradicate than biofilm that is thicker but consists of a lower number of cells. Of course, the above-mentioned considerations are valid if we assume that the level of emitted fluorescence is the same (or at least approximately the same) for every cell in the biofilm, regardless of its physiological state and spatial location within the biofilm. Unfortunately, the performance of an experiment aiming to check the aforementioned possible differences is far beyond the technological possibilities offered by contemporary technology. 
Thickness of A (z1) is higher than thickness of B (z2); while number of cells is higher in B) than in A). Measured fluorescence level is higher in B) than in A) thanks to higher density of cells within measured region of interest.

B)

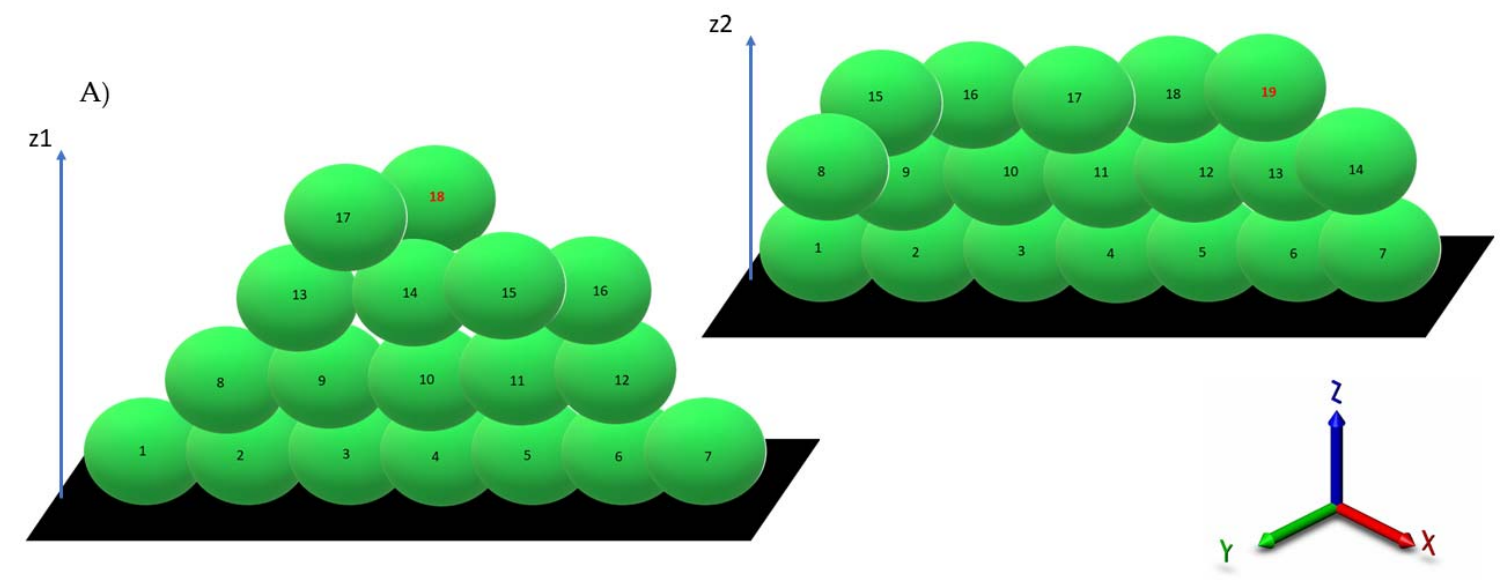

Figure 7. An attempt at explanation of the data presented in Table 1. Because of various cellular density between A) and B) parts of biofilm, the level of fluorescence of biofilm B) is higher than that of biofilm A), although biofilm A) is thicker (4 "layers") than biofilm B), which consists of 3 "layers". z1, z2 - Z-axis showing biofilm thickness; green oval shapes SYTO-9-dyed staphylococci emitting fluorescence; numbers in the central points of oval shapes show a higher number of cells in biofilm A) in comparison to biofilm B).

The key point from the data presented in Figures from 1 to 7 is that differences in staphylococcal biofilm formed in vitro are caused not only by intra-species variability, but also by the differentiation of individual structures formed by particular strains. Thus, it should not be analyzed as a homogeneous structure of highly repeatable features. The main features of staphylococcal biofilm, which were recurring constantly during our observations and which are important from the point of view of the matter discussed, are presented in Table 2. 
Tab.2. Main characteristics of staphylococcal biofilm in vitro.

\begin{tabular}{|l|l|}
\hline Parameter(s) & Characteristics \\
\hline confluency & very high confluency. Rare areas non-covered with cells ("holes") \\
the "hill-like" character
\end{tabular}

The determination of the main characteristics of staphylococcal biofilm in vitro, performed in the first part of this research, not only revealed important common denominators of this structure (formed by different strains), but was also necessary to properly demonstrate the impact of subsequent steps of biofilm sample's preparation on the outcome obtained. Thus, the issues aimed to be elucidated in this section of manuscript were the result of rinsing of staphylococcal biofilm in vitro. The procedures of introduction and removal of liquids to and from the culture vessels are one of the most recognized disadvantages of microplate-based methods in general, as they lead to random de-attachment of biofilm [37]. With regard to the images and parametric data obtained by means of confocal/epifluorescent microscopy, such de-attachment is of paramount (and negative) importance, because it leads to the formation of random holes in the biofilm structure which may be interpreted as resulting from the eradicative force of the introduced antiseptics. The standard procedure of analysis of antiseptic impact on biofilm in vitro includes at least 11 steps of liquid introduction and removal. These are: i) aspiration of medium, ii) introduction/removal of rinsing liquid, iii) introduction/removal of antiseptic agent, iv) introduction/removal of antiseptic neutralizer, v) introduction/removal of L/D mixture, vi) introduction/removal of rinsing liquid). Noteworthy, the number of steps may be higher, because specific protocols recommend to repeat specific steps (mostly ii and vi) twice or three times. Figure 7 presents the powerful impact of just a single step (medium removal (i)) on the spatial distribution of the staphylococcal biofilm during 90 seconds of observation. The de-attached fragments of biofilm migrate, drifting in the liquid, re-shaping the 
architecture of the remaining, more firmly attached cellular aggregates. The processing of the initial (15 sec.) and the final image frame (90 sec.) with the use of imageJ software indicated (Figure 7, lower panel) that areas covered with cellular structures (detected above the established threshold, equal for both frames) differed by $10.091 \%$ and by $23.027 \%$ with regard to the Mean Grey Value (MGV) units. Noteworthy, this difference was recorded when just a single (out of, at least, 11 remaining) steps of washing was applied. It can thus be stated that the alteration of biofilm structure when all the remaining steps are applied (bearing also in mind the fact that one of them, antiseptic agent introduction, leads to the destruction of cells) are of a massive, and rather unpredictable, character. In our opinion it is one of the most important variables during the whole process of assessment of antiseptic agent impact on staphylococcal biofilm in vitro. The fact that some research teams recommend rinsing the plates with tap water or shaking the plate out over a waste tray [38], additionally and rather strongly impedes the obtaining of repeatable and conclusive results.
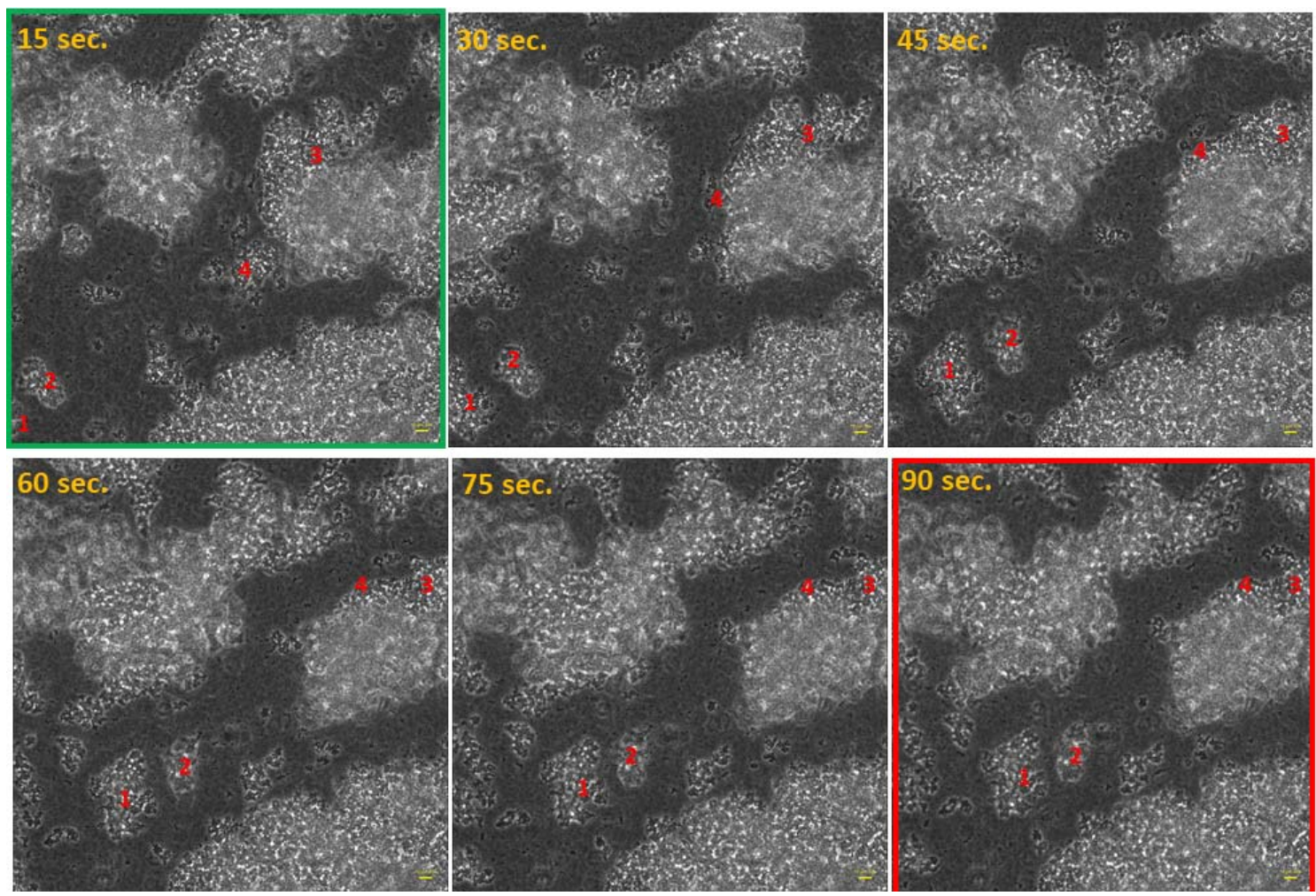


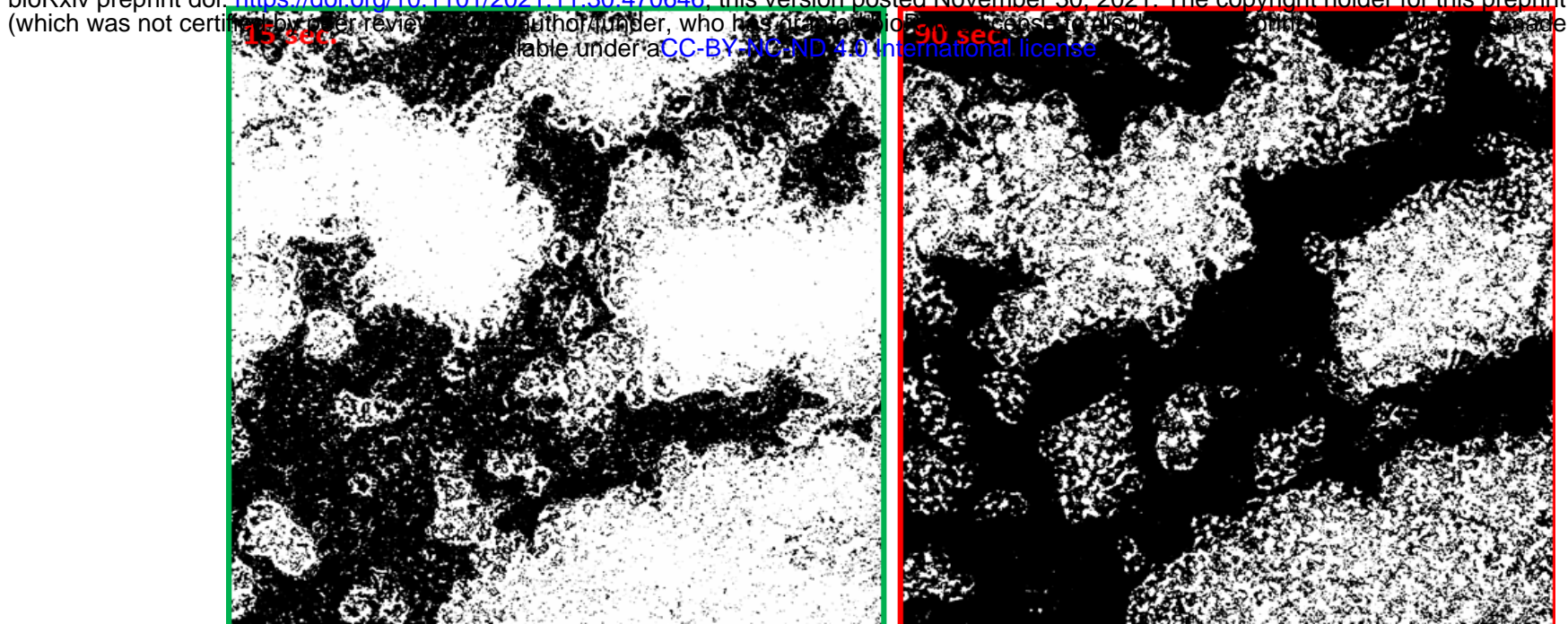

Figure 7. The impact of medium removal on the distribution of staphylococcal (ATCC33591) biofilm within 90 seconds of observation. Numbers 1-4 designate exemplary staphylococcal cell aggregates drifting over time and re-shaping biofilm structure. The lower panel presents changes in staphylococcal biofilm distribution following the implementation of image processing software. The scale bar is $10 \mu \mathrm{m}$, magn.40x, microscope Lumascope 600. Please click the https://www.youtube.com/watch?v=uwTtHIurDfw\&t=24s to watch a video showing the process of biofilm de-attachment.

Nevertheless, the processes of liquid introduction and removal cannot be omitted, if L/D dyeing is to be performed. The solutions aiming to decrease, to some extent, the negative impact of rinsing on the reproducibility of results involve: i) gentle aspiration and removal of liquid during manual pipetting, ii) placing the tip of the pipette in the same position (preferably on the rim of the plate's well), iii) if possible, reducing the number of rinsings, and, last but not least, the performance of an appropriate number of technical repeats and independent experiments (performed in accordance with the general methodology of biological quantitative experiments). The first-mentioned parameter is highly operator-related, requires laboratory practice and is hard to be parametrically defined. Nevertheless, examples of how the outcome of biofilm distribution throughout the plate's well may differ depending on the operators' specific pipetting habits are presented in Figure $\mathbf{8}$ to underline the importance of the matter discussed. The modifications of the rinsing procedure and pipetting, which have led to the high reproducibility of outcomes obtained by our research team (presented in Figure 8D) and to a drop in random de-attachment of biofilm are specified in Material and Methods 3.2. Section of this manuscript. With regard to further image processing, the regions approximate to the place where the pipette was introduced (marked as a red cross in Figure 8) and the rim of the well, should be considered as having lower usability (due to deviations in biofilm distribution being a result of strong shearing forces). 
A

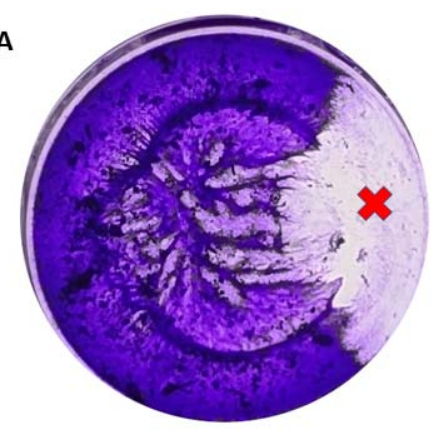

C

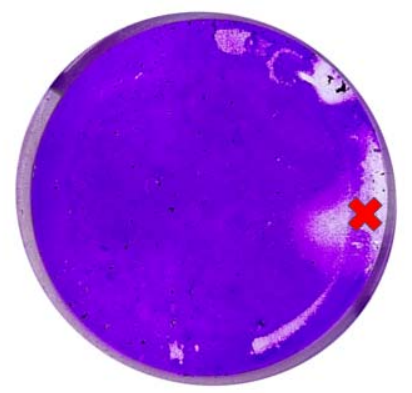

B

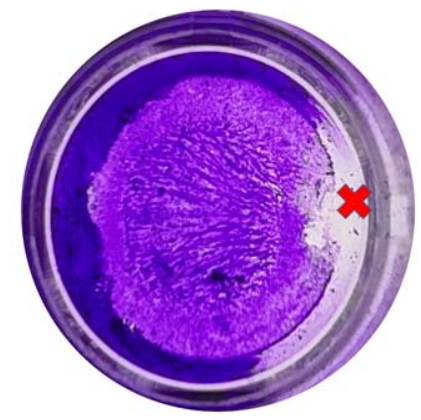

D

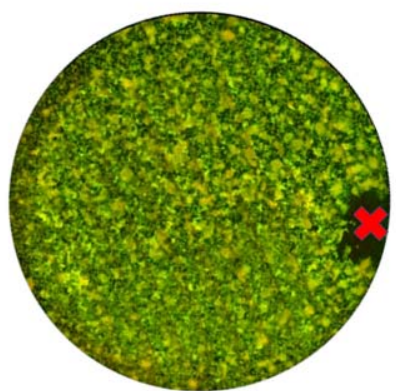

Figure 8. The impact of operators' various pipetting habits $(\mathrm{A}, \mathrm{B}, \mathrm{C})$ on dye distribution in the well (of a 24-well plate) covered with biofilm formed by the same staphylococcal strain (ATCC 6538). Picture D presents the biofilm of the aforementioned strain dyed with the L/D method by an operator with 3 years of experience in staphylococcal biofilm culturing and dyeing. The red cross indicates the approximate place of pipette tip placement.

The process of rinsing is of paramount importance not only due to the impact on the staphylococcal biofilm structure and confluency but also because it correlates with an un-even change in the fluorescence intensity level measured for SYTO-9 ("live") and PI ("dead") cells. This statement is another of the major discoveries made in the present study because it re-defines the usability of the last-mentioned dye for the analyses of the impact of antiseptic agents on staphylococcal biofilm. As can be seen in Figure 10, the subsequent rinsing steps lead to a significantly stronger reduction of the PI fluorescence level compared to the reduction in the SYTO-9 fluorescence level. We hypothesize that the reason behind this phenomenon is the fact that PI binds to damaged/compromised cells (examples of such cells are presented in the right panel of Figure 10), which are more vulnerable to be flushed out by the introduced liquid. 

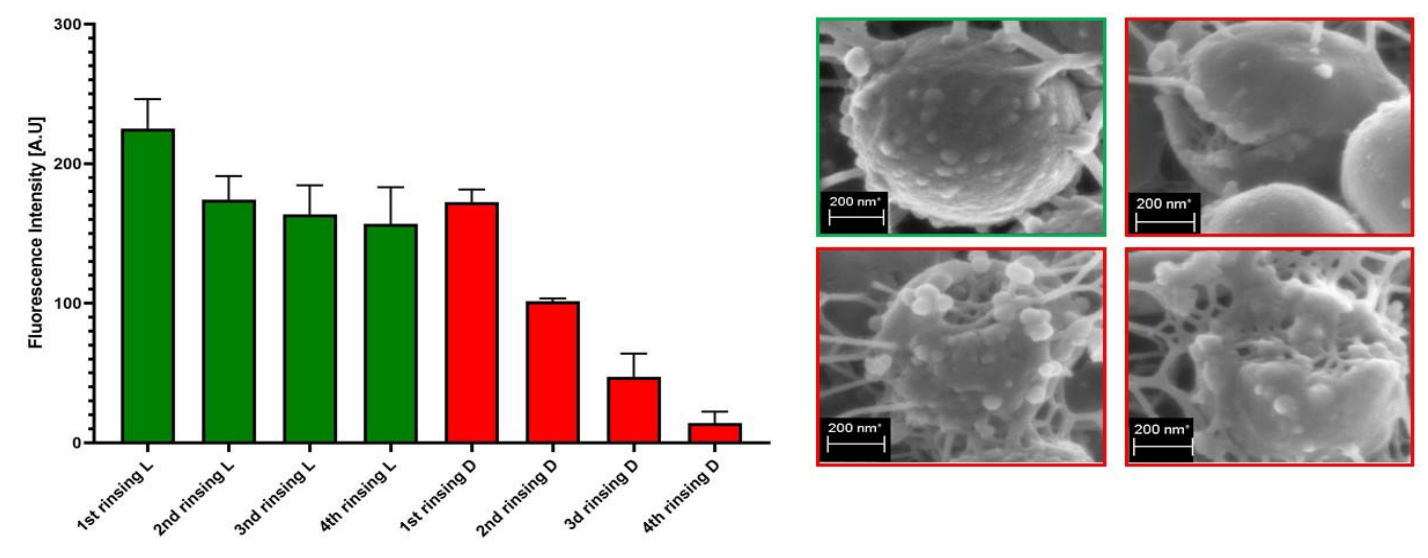

Figure 9. The impact of subsequent rinsing steps on fluorescence intensity of SYTO-9 (L) and PI-dyed (D) biofilm-forming cells of the ATCC6538 strain. The right panel shows staphylococcal cells of an intact cellular wall (green frame) and staphylococcal cells of an increasing level of cell wall damage (red frames). The scale bar is $200 \mathrm{~nm}$. Magnification 100000x, Microscope Auriga 60.

The general concept of application of these two dyes is based on the idea that the activity of an antimicrobial should correlate with a drop in fluorescence level from SYTO-9 dyed cells with a simultaneous increase in the fluorescence level from PI-dyed cells. However, the observation from this study (Figure 9) explicitly shows that PI is of lower usability for parametric analyses of staphylococcal biofilm in vitro than the SYTO-9 dye. In our opinion, the application of PI may be valid for images of a high aesthetic value, while the parametric measurement of the viability of staphylococcal, biofilm-forming cells should be performed with the use of SYTO-9 only (by comparison of the levels of SYTO-9 fluorescence between biofilm treated with antimicrobial and untreated, control biofilm). The above statement is particularly valid with regard to these antiseptic agents which disintegrate the continuity of staphylococcal cell walls [39]. In turn, the verification of the discovery presented in Figure 9 with regard to bacteriostatic agents undoubtedly requires an experimental confirmation. Noteworthy, the proposal of the application of only SYTO-9 for measuring the drop in biofilm's viability resembles the methodology applied in normative analyses of eukaryotic cell lines (cytotoxicity tests, for example), where the drop in live cells (dyed with tetrazolium salts) is measured after biocide introduction and compared to the un-treated control [40]. We are also aware of the fact that within biofilm structure, a certain population of cells is 
considered to be "viable, but non-culturable" (VNBC; such cells display a higher resistance to antimicrobials than viable, culturable cells). Because SYTO-9 binds to the VNBC cells, the measured level of fluorescence in the untreated control may include also fluorescence from these cells. On the other hand, such cells are still considered "infective" (and able to cause for example, aseptic loosening of an implant [41]), so their detection as part of infective biofilm should be considered valid. The main discoveries from the data presented in Figures 7-9 are presented in Table 3 .

Table 3. Main preparative/process variables associated with the deviation in the obtained results and the suggested, counter-actions.

\begin{tabular}{|c|c|c|}
\hline Parameter/process/phenomenon & Characteristics & Action \\
\hline $\begin{array}{ll}\text { rinsing } & \text { (liquid } \\
\text { introduction/removal) } & \end{array}$ & $\begin{array}{l}\text { randomly re-shapes } \\
\text { biofilm architecture }\end{array}$ & $\begin{array}{l}\text { a) perform with } \\
\text { precaution; } \\
\text { a) if possible, standardize } \\
\text { all sub-steps (place of } \\
\text { pipette placement, } \\
\text { force of liquid } \\
\text { introduction/removal) } \\
\text { b) perform preliminary } \\
\text { studies to check } \\
\text { whether the number of } \\
\text { rinsing steps may be } \\
\text { reduced without } \\
\text { compromising the } \\
\text { quality of the } \\
\text { performed analyses } \\
\text { due to rheological } \\
\text { phenomena, the rim of } \\
\text { the well and } \\
\text { approximate region of } \\
\text { pipette placement is of } \\
\text { low usability for } \\
\text { subsequent image } \\
\text { processing a single } \\
\text { engage a biofilm } \\
\text { operator into the entire } \\
\text { process of bi antiseptic } \\
\text { culturing, and } \\
\text { introduction, } \\
\text { biofilm dyeing }\end{array}$ \\
\hline $\begin{array}{l}\text { PI dye is of lower applicability } \\
\text { than SYTO-9 }\end{array}$ & $\begin{array}{l}\text { PI dye is removed from } \\
\text { the experimental setting to } \\
\text { a higher extent than } \\
\text { SYTO-9 }\end{array}$ & $\begin{array}{l}\text { a) consider the } \\
\text { application of SYTO-9 } \\
\text { only and compare the } \\
\text { fluorescence level of }\end{array}$ \\
\hline
\end{tabular}




\begin{tabular}{|l|l|l|}
\hline & $\begin{array}{l}\text { SYTO-9-dyed biofilm } \\
\text { treated with antiseptic } \\
\text { to } \text { SYTO-9-dyed } \\
\text { biofilm non-treated } \\
\text { with antiseptic }\end{array}$ \\
\hline
\end{tabular}

The data summarized in Table 2 and Table 3 were necessary to get a proper perspective on the main aim of this research and they allow a deeper understanding of the phenomena occurring during the introduction of an antiseptic agent into the staphylococcal biofilm in vitro presented in Figure 10.
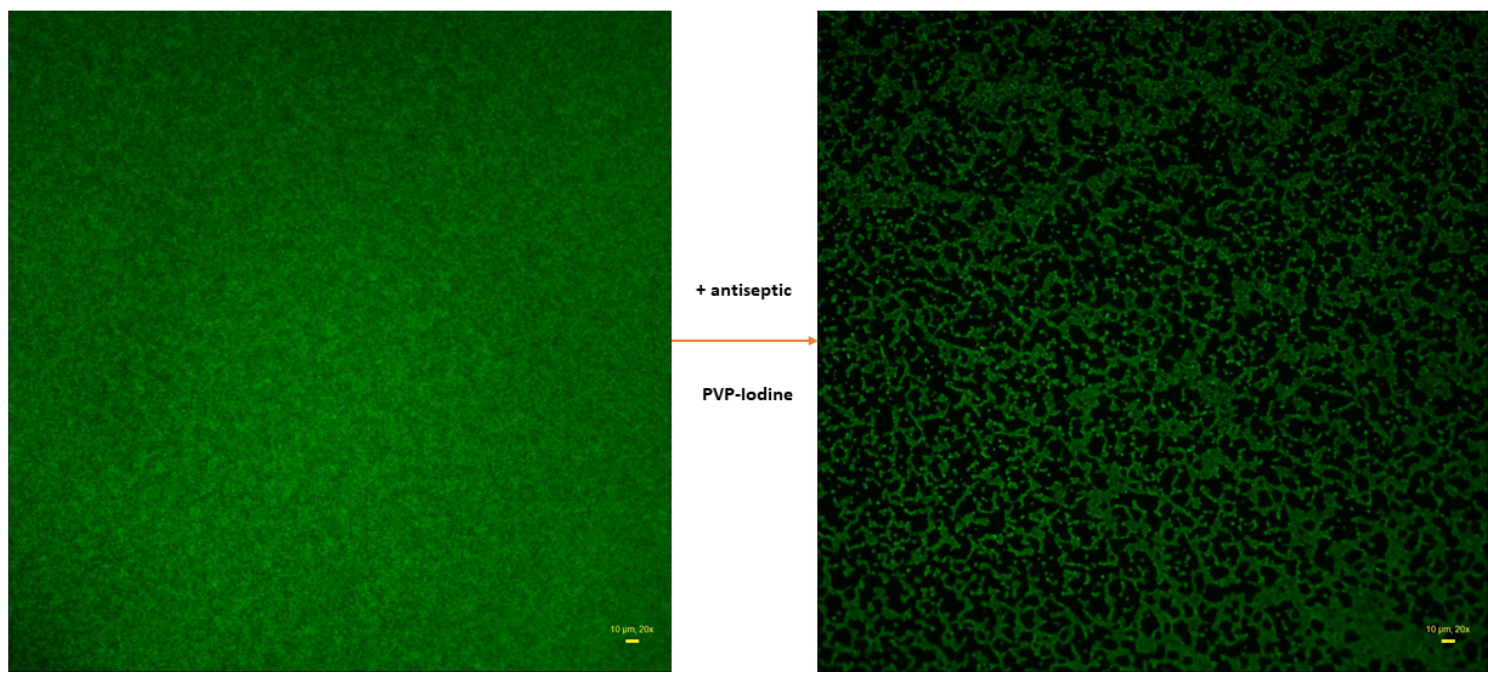

Figure 10. Staphylococcal biofilm of the same strain non-treated (left picture) and treated (right picture) with an antiseptic (PVP-iodine). Biofilms dyed with SYTO-9 only. Aerial perspective, epifluorescent microscopy,Lumascope 600 magn. 20x, scale bar is $10 \mu \mathrm{m}$. 
The main differences observed between the two pictures in Figure $\mathbf{1 0}$ are: i) drop in confluency of treated biofilm and ii) drop in the fluorescence level of treated vs. non-treated

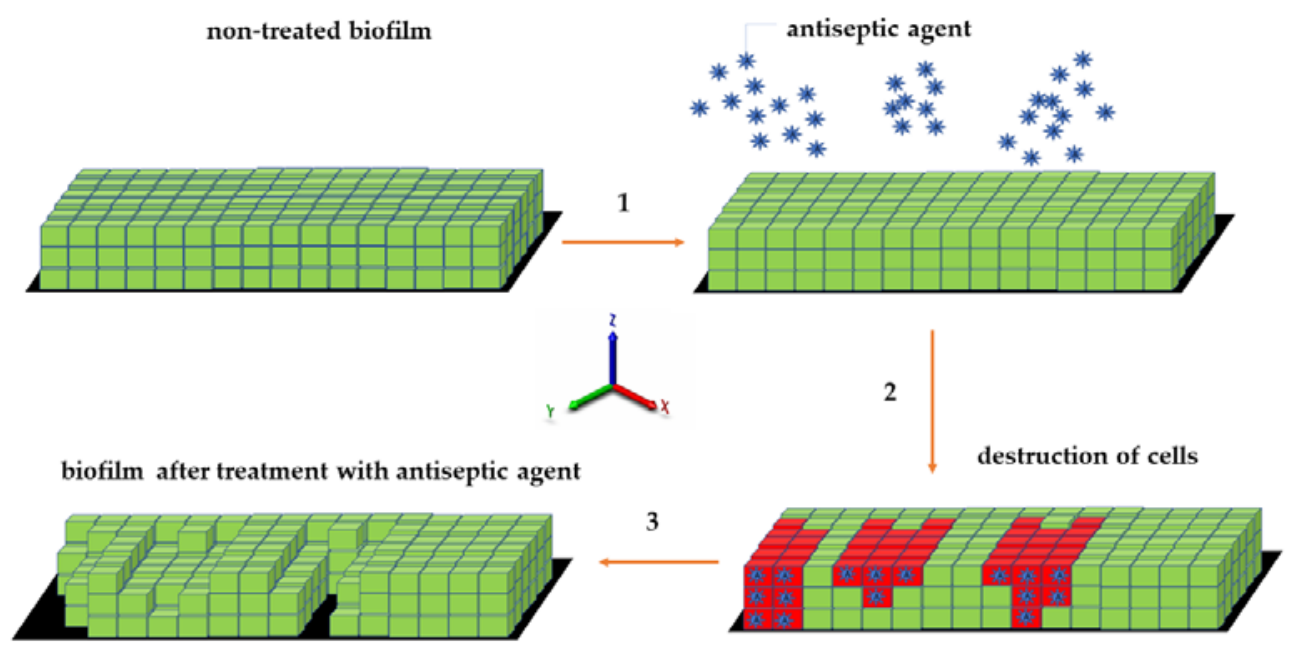

biofilm.

A

B

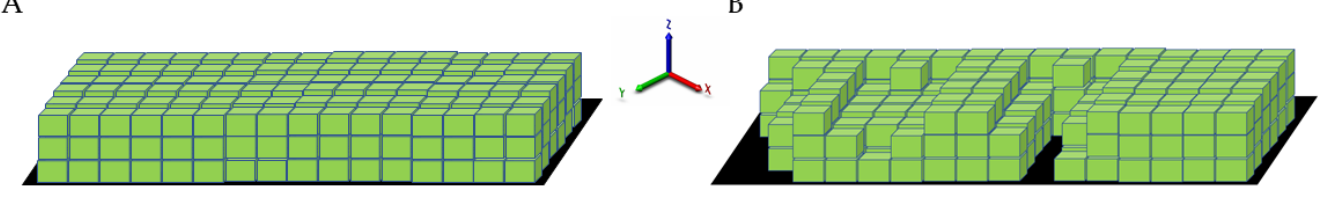

C

$\mathrm{D}$

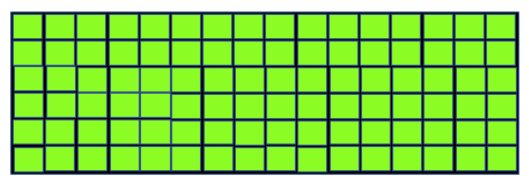

top view $-x y$ plane

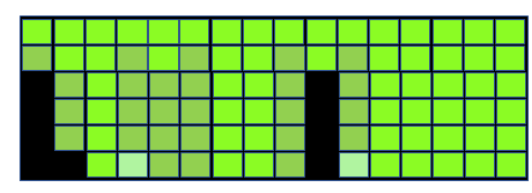

biofilm of intact cellular density

biofilm of decreased cellular density in result of antiseptic agent's activity

Biofilm of strongly decreased cellular density in result of antiseptic agent's activity

Area without cells (in result of antiseptic agent's activity and/or rinsing procedures

Figure 11. Schematic presentation of the phenomena occurring during antiseptic activity against biofilm reflected in the formation of "holes" and in a drop in fluorescence intensity. For picture clarity sake, the staphylococcal cells are shown as cubes, while intact 
biofilm formed by the cells is presented as an even (with regard to height) structure. 1) introduction of antiseptic agent to biofilm; 2) antiseptic agent activity; 3) destruction of cells (resulting from antiseptic agent activity) and removal of cells (resulting from antiseptic agent activity and rinsing). A,C -intact biofilm in 3D and -xy plane, respectively; B,D - biofilm after the application of antiseptic in 3D and -xy plane, respectively.

The drop in confluency as well as the fluorescence level may result from rinsing procedures (Figure 7) during biofilm dyeing but also, in this particular situation, from the antimicrobial activity of the antiseptic applied. At first glance, non-treated biofilm seems to be fully confluent (Figure 10, left picture). However, a more detailed observation reveals regions of higher and lower fluorescence (brighter vs. darker green areas, respectively), suggesting that also in this case, rinsing leads to the removal of some of biofilm-forming cells. A schematic explanation of the phenomena occurring during the introduction of antiseptics, resulting in specific types of images from confocal or epifluorescent microscope, is presented in the upper and lower panel of Figure 11, respectively. On the basis of the summarized data collected (Table 2, Table 3 and Figure 11) and image processing tools (such as ImageJ) it is possible to derive a mathematic formula enabling to assess the level of the impact of an antiseptic on staphylococcal biofilm. The formula should consist of two components, the first of which should deal with confluency changes, while the second one with the changes in live cells number (measured indirectly with the SYTO-9 dye). Therefore, the first component is described as Biofilm-Covered Area (BCA), assessed as the percentage [\%] of culture-well area which is covered by adherent cells. Although it does not differ from the confluency parameter assessed for eukaryotic cells, one should remember that in the case of standard eukaryotic lines in vitro we deal with a monolayer of cells, while BCA describes a region of multi-layered bacterial cells, along the X, Y and — importantly —along the $\mathrm{Z}$ axis. The exemplary image processing leading to BCA [\%] calculation by means of ImageJ is presented in Figure 12. As an effect of this action, only areas above an established threshold value are considered to contain biofilm-forming cells, while the remaining areas are considered cell-free (the "holes", non-fluorescent areas). 

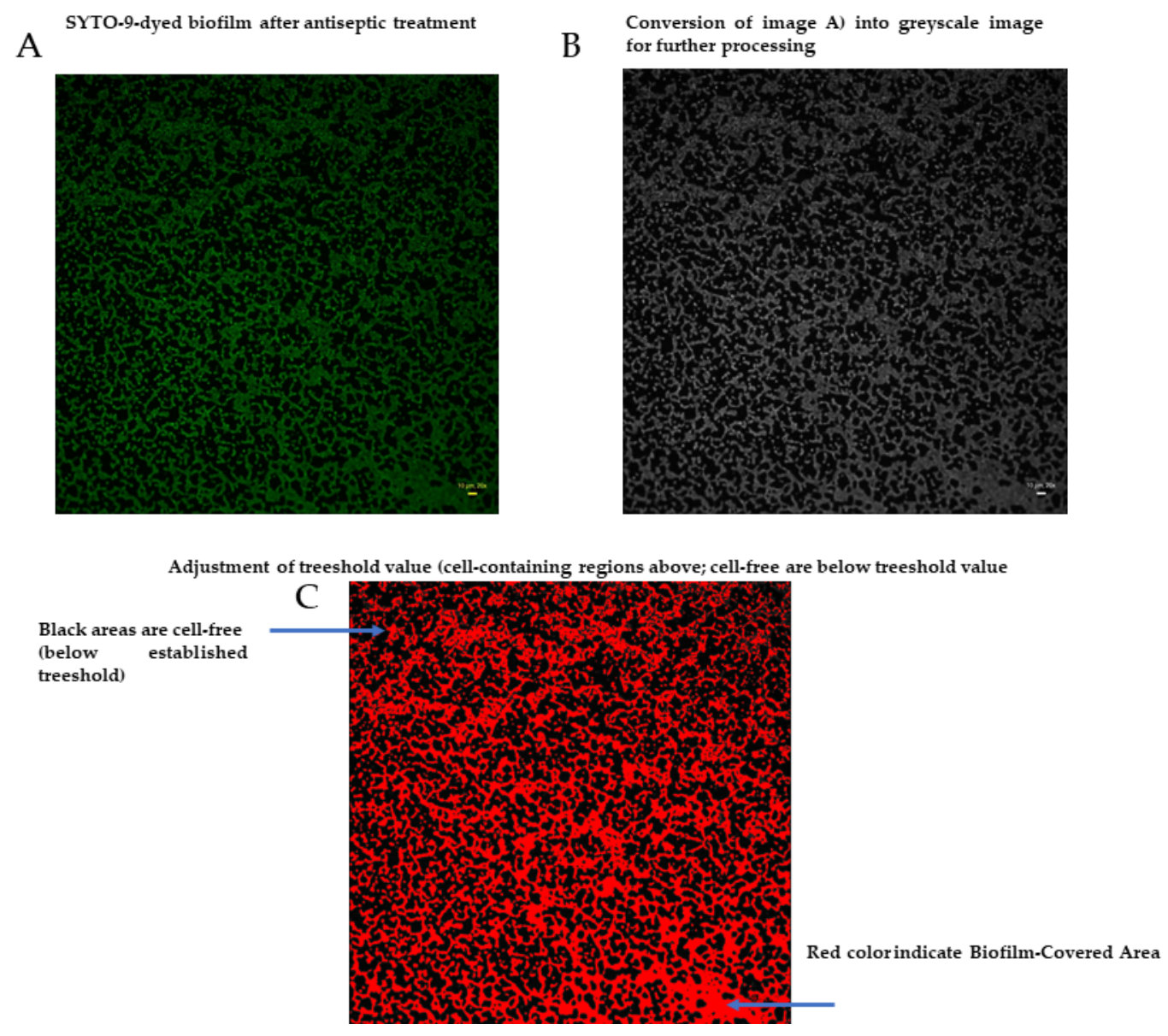

Figure 11. Processing of biofilm image to extract the value of Biofilm-Covered Area [\%]. A - biofilm after treatment with antiseptic; B,C - processing stages aiming to extract the value of BCA [\%].

The BCA [\%] calculated for the biofilm treated with antiseptic (Figure 11) was 49\%, while for the biofilm of the same strain, non-treated with antiseptic (Figure 9, left picture), this value was $99 \%$. In other words, the antiseptic activity correlated with a drop in BCA [\%] value by $50 \%$ $(99 \%-49 \%)$.

The second parameter necessary to be introduced to the formula is a drop in cell number in the BCA. While in the case of the earlier analyzed parameter, the antiseptic penetrated and killed all the cells in a specific region along the $\mathrm{Z}$ axis (from $\mathrm{T}$ to $\mathrm{B}$ part of the biofilm), leaving black, non-fluorescent areas, in the case of the second parameter, referred to as the Biofilm Fluorescence Intensity Drop (BFID), the antiseptic activity led to the death of a certain number of cells (but not all of them) within specific regions. As a result of such type of action, the cellular density within specific region drops, but some cells are able to survive. 
As the total cell number decreases, the Fluorescence Intensity (FI) decreases as well (please compare fluorescence intensity of non-treated vs. treated biofilm in Figure 10). To calculate the BFID, the FI of treated biofilm-covered areas is then compared to the fluorescence of nontreated biofilm areas. Noteworthy, BFID is calculated only for Biofilm-Covered Area, not for black, non-fluorescent regions. Following the example of biofilms presented in Figure 10, FI of BCA of treated biofilm and non-treated biofilm (BCA regions) is 44.99 vs. 104.38, respectively. It means that FI in antiseptic-treated BCA constitutes a fraction of 0.43 , i.e. $44.98 / 104.38$ of the non-treated biofilm. The BCA value of treated biofilm was $49 \%$, so the fluorescence level in this area was decreased by $21.07 \%(0.43 \times 49 \%)$. Therefore, the antiseptic activity against this not completely eradicated biofilm can be expressed as the BFID equal $49 \%-21.07 \%=27.93 \%$. Combining the BCA and BFID components, the following formula of Antiseptic's Biofilm Eradication (ABE [\%]) is achieved:

$$
\begin{aligned}
\mathrm{ABE}[\%]=( & \left(\mathrm{BCA}_{\text {non-treated biofilm }}-\mathrm{BCA}_{\text {treated biofilm }}\right) \\
& +\left(\mathrm{BCA}_{\text {treated biofilm }}-\frac{\mathrm{FI}_{\text {treated biofilm }}}{\mathrm{FI}_{\text {non-treated biofilm }}} \times \mathrm{BCA}_{\text {treated biofilm }}\right)
\end{aligned}
$$

and after simplification:

$$
\mathrm{ABE}[\%]=\mathrm{BCA}_{\text {non-treated biofilm }}-\frac{\mathrm{FI}_{\text {treated biofilm }}}{\mathrm{FI}_{\text {non-treated biofilm }}} \times \mathrm{BCA}_{\text {treated biofilm }}
$$

Therefore, the ABE [\%] for the exemplary staphylococcal biofilm treated with PVP-I (Figure 10) is $78.77 \%$.

The $\mathrm{ABE}[\%]$ takes into account all data and phenomena detected and revealed within the course of this study, reducing their quite abstruse character to a simple mathematic formula. Having the ABE [\%] established, the assessment of the effect of exemplary antiseptics (PHMB, PVP-I and $\mathrm{NaOCl}$ ) on staphylococcal biofilm of all 10 scrutinized strains was performed (Figure 12). 


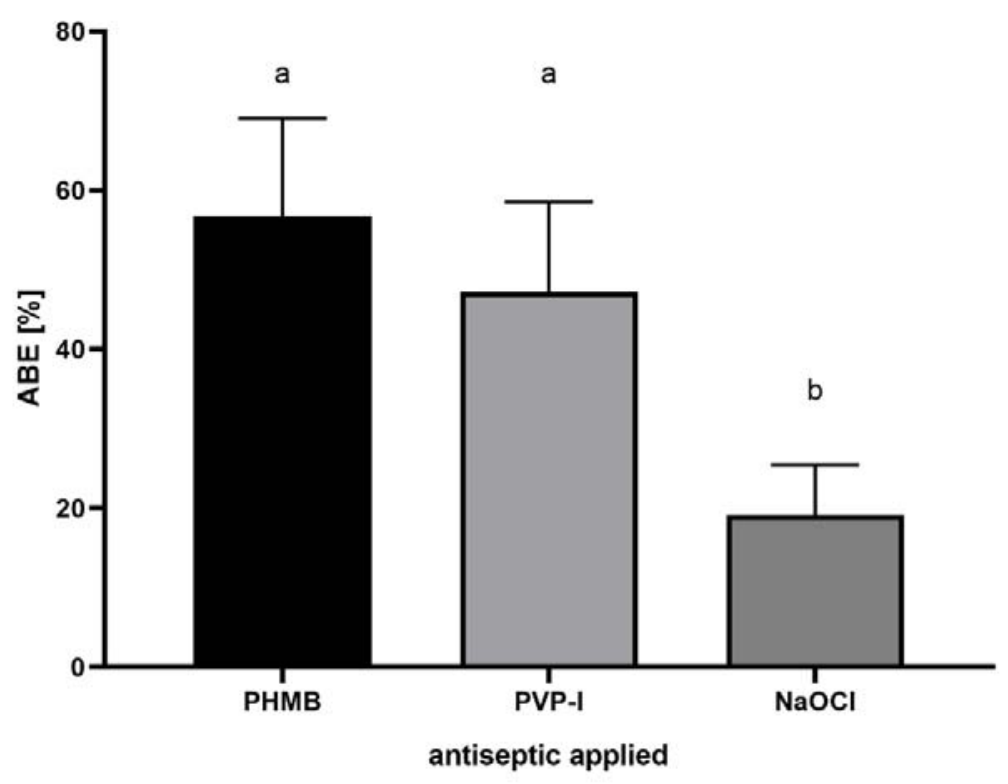

Figure 12. ABE $[\%]$ value recorded for polyhexamethylene (PHMB), povidone-iodine (PVPI) and hypochlorite solution $(\mathrm{NaOCl})$ towards staphylococcal biofilms $(\mathrm{n}=10)$ formed in vitro. ABE [\%] - Antiseptic's Biofilm Eradication

The results presented in Figure 12 show comparable antibiofilm activity of PHMB and PVP, and a statistically higher ( $p>0.5)$ activity of these compounds in comparison to the $\mathrm{NaOCl}$ activity. Such a result, presented in the form of ABE [\%] value developed in this research confirms the methodological usability of this parameter as it stays in line with the data presented by our and other teams concerning the activity of these 3 wound antiseptics $[9,42,43]$; especially the lack of effectiveness of $\mathrm{NaOCl}$, containing low, $80 \mathrm{ppm}$ hypochlorite content, showed already by Severing et al. [44]. Thus, by research performed in this study we have developed not only a new tool to assess the antiseptic activity against staphylococcal biofilm $(\mathrm{ABE}[\%])$, but also, on a general level, we have provided another data-set confirming the usability of microscopic analysis combined with image processing in studies on antiseptics.

To reach this aim, we have gone a long experimental way and encountered numerous variables of the impact on the results obtained. Their analysis revealed new variables. One of the conclusions from this research line (of a very general character) is that presumably, the 
number of variables related with biofilm culturing coupled with image processing, starts to surpass the capability of research teams and requires support from Artificial Intelligence algorithms to be analyzed properly [45]. Although our research may be considered an important step towards complex analyses of antiseptics' activity against staphylococcal biofilms, we are also aware of certain disadvantages of our work. Firstly, to keep the number of variables under control, we analyzed basically only $24 \mathrm{~h}$-old biofilms. We are conscious of the fact that if we had analyzed "younger" and "older" biofilms we could have obtained also other than detected patterns of cellular density, biofilm thickness and L/D-dyed cell spatial composition. Secondly, we applied just one type of culturing medium (Tryptic Soy Broth), while high differences in biofilm structures formed by the same strain, but cultured in different media, were already observed [46]. Thirdly, we cultured biofilms on the polystyrene surface only, while the impact of surface type on biofilm structure is undisputable and proven [47]. As mentioned, our aim was to keep the number of variables under control, therefore we performed analyses in one particular setting (24h biofilm, TSB medium, polystyrene surface). Nevertheless, this manuscript and data presented in it could be already perceived as too extensive. The implementation of additional variables would force us to make it significantly longer and more complex. Still, we are convinced that the range of already performed analyses indicates the directions of subsequent paths that may be explored by other research teams with an aim to increase our knowledge of the phenomena occurring when staphylococcal biofilm is exposed to an activity of locally acting antiseptic agents.

\section{Materials and Methods}

\subsection{Antiseptics applied}

a) Prontosan wound irrigation solution ${ }^{\circledR}$ (B. Braun, Melsungen, Hessen, Germany), composed of purified water, $0.1 \%$ betaine surfactant, and $0.1 \%$ polyaminopropyl biguanide (polyhexanide), later referred to as PHMB;

b) Granudacyn ${ }^{\circledR}$ Wound Irrigation Solution (Molnlycke Health Care AB, Göteborg, Sweden), composed of water, sodium chloride, $0.005 \%$ sodium hypochlorite, and $0.005 \%$ hypochlorous acid, later referred to as $\mathrm{NaOCl}$;

c) Braunol® (B. Braun, Melsungen, Hessen, Germany), composed $7.5 \%$ povidone $\square$ iodine with $10 \%$ available iodine, sodium dihydrogen phosphate dihydrate, 
sodium iodate, macrogol lauryl ether, sodium hydroxide, and purified water, later referred to as PVP $\square \mathrm{I}$.

\subsection{Staphylococcal strains and biofilm culturing in vitro}

Two reference strains from the American Type Culture Collection (ATCC), Staphylococcus aureus 6538 and 33591, and 8 clinical strains isolated from chronic wound infections were chosen. All staphylococcal strains are part of collection of the Department of Pharmaceutical Microbiology and Parasitology of Wroclaw Medical University, collected during research project approved by the Bioethical Committee of Wroclaw Medical University, protocol \# 8/2016. The strains were transferred from Columbia Agar (Biomaxima, Lublin, Poland) to liquid Tryptic Soya Broth (Biomaxima, Lublin, Poland) and incubated for $24 \mathrm{~h} / 37^{\circ} \mathrm{C}$. Next, they were diluted using densitometer (Densilameter II, Erba Lachema, Brno, the Czech Republic) to $0.5 \mathrm{McF}$ arland and with serial dilution to ca. $10^{5} \mathrm{cfu} / \mathrm{mL}$. The number of cfu was additionally checked by quantitative culturing on Columbia Agar. $2 \mathrm{~mL}$ of staphylococcal suspensions of $10^{5} \mathrm{cfu} / \mathrm{ml}$ were transferred to the wells of the 24-well plate (Wuxi Nest Biotechnology, Wuxi, China) and incubated for $24 \mathrm{~h} / 37^{\circ} \mathrm{C}$. After that, the medium containing planktonic cells was gently removed, and the well was rinsed once with saline (Stanlab, Lublin, Poland). Such prepared biofilms were subjected to subsequent analyses. Above methodology applied in all cases with except: - setting presented in Figure 1A, where biofilm was cultured for 12 hours

- setting presented in Figure 2 where biofilm was cultured for 24 hours but inside of microscopic glass (Medical Depot, Warsaw, Poland).

- setting presented in Figure 7, where medium was removed from 24-old biofilm and the images were taken using bright light vision in Etaluma Lumascope 620 fluorescent microscope (San Diego, CA, USA)

- setting presented in Figure 3S, where medium was removed from 24h-old biofilm to capture the macro-image of undyed biofilm structure.

\subsection{Live/Dead dyeing of staphylococcal biofilms and microscopic visualization}

Staphylococcal biofilms, cultured as presented in Materials and Methods 3.2. were dyed with $500 \mu \mathrm{L}$ of Live/Dead solution ( Filmtracer ${ }^{\mathrm{TM}}$ Live/dead $^{\mathrm{TM}}$ Biofilm Viability Kit, Thermo Fisher Scientific, Waltham, MA, USA) according to the protocol provided by the 
manufacturer. After 20 minutes of incubation without light, the dyeing solution was gently removed and rinsed once with filter-sterilized water. Such prepared samples were subjected to subsequent analyses. The microscopic visualizations were performed with use of Leica SP8 MP confocal microscope (Leica, Wetzlar, Germany), Etaluma Lumascope 620 fluorescent microscope (San Diego, CA, USA) and confocal microscope Zeiss Cell Observer SD (Oberkochen Germany). The analysis was performed using $488 \mathrm{~nm}$ laser line and 500-530 $\mathrm{nm}$ emission to visualize SYTO-9 and $552 \mathrm{~nm}$ laser line and 575-627 nm emission to visualize propidium iodide (PI), in a sequential mode. Images are maximum intensity projections obtained from confocal $\mathrm{Z}$ stacks with $\sim 2 \mu \mathrm{m}$ spacing in $\mathrm{Z}$ dimension. PI is represented in red/orange and SYTO-9 in green color. The obtained biofilm images were further analyzed using Imaris 9 (Abingdon, UK) software.

\subsection{Scanning Electron Microscopy Analysis}

The biofilms were cultured in the analogical manner as described in Materials and Methods 3.2., with such a difference that the polystyrene coupons were placed in the bottom of the 24well plate and served as the surface for staphylococcal biofilm growth. Next, The samples were gently cleansed in PBS (Sigma-Aldrich, Darmstad, Germany) buffer as it was described in; fixed in glutaraldehyde [28] (POCH, Wroclaw, Poland) and dried in a critical point dryer EM CPD300 (Leica Microsystems, Wetzlar, Germany). Subsequently, the samples were subjected to sputtering with $\mathrm{Au} / \mathrm{Pd}$ (60:40) using EM ACE600, Leica sputter (Leica Microsystems, Wetzlar, Germany). The sputtered samples were examined using a scanning electron microscope (SEM, Auriga 60, Zeiss, Germany).

\subsection{Staining staphylococcal biofilms with Violet Crystal method}

The 0.5 McFarland density of the bacteria suspension in TSB medium was prepared and next diluted to $1 \times 10^{5} \mathrm{CFU} / \mathrm{mL}$. A total of $1 \mathrm{~mL}$ of the suspension was added to the well of a 24 $\square$ well microtiter plate (Wuxi Nest Biotechnology, Wuxi, China) and incubated for $24 \mathrm{~h}$ at $37{ }^{\circ} \mathrm{C}$. Subsequently, the non $\square$ adhered cells were removed, and the plate was dried for 10 min at $37{ }^{\circ} \mathrm{C}$. Next, $1 \mathrm{~mL}$ of $20 \%$ (v/v) water solution of crystal violet (Aqua $\square$ med, Lodz, Poland) was added, and the mixture was incubated for $10 \mathrm{~min}$ at room temperature. After incubation, the solution was removed, the biofilm was gently washed twice with $100 \mu \mathrm{L}$ of $0.9 \% \mathrm{NaCl}$ (Stanlab, Lublin, Poland), and dried for the next $10 \mathrm{~min}$. Next, the image of dyed biofilm was captured photographically. 


\subsection{Impact of rinsing on intensity of SYTO-9 and propidium iodine.}

The procedures were performed as in Material and Methods 3.2. and 3.3. with such a difference that rinsing with water performed once, twice, three or four times. After every rinsing the analysis with use of Etaluma Lumascope 620 fluorescent microscope (San Diego, CA, USA) as performed in Material and Methods 3.3. to capture the changes in Fluorescence Intensity from SYTO-9 and propidium iodine dyes.

\subsection{Image processing of staphylococcal biofilms using ImageJ software}

The captured biofilm pictures were processed using ImageJ (National Institutes of Health, Bethesda, MD, USA) First, RGB pictures were divided into green and red channel sub-images and subsequently changed into 32-bite grey types. Next, the mean grey value was extracted from images of every type. The mean grey value correlates with the value of fluorescence intensity and it is defined as the sum of the values at all pixels divided by the number of pixels. For clarity sake, the OY axes in the Figures dealing with intensity values are presented as Fluorescence Intensity.

In case, when application of ABE [\%] formula required the assessment of BCA [\%] (BiofilmCovered Area), the images were changed into 32-bite grey type, next the Threshold option was applied to differentiate the region of interest (staphylococcal biofilm) from the areas noncovered with biofilm (referred to as the "Background"); subsequently the options Analyze$>$ Set Measurements->Area was applied to calculate percentage of area covered with biofilm.

\subsection{The assessment of Antiseptic Biofilm Eradication value}

The staphylococcal biofilms were cultured as described in Material and Method 3.2., each strain in 6 repeats. After medium removal, $1 \mathrm{~mL}$ of antiseptic (PHMB, NaOCL or PVP-I) was introduced for 1 hour. Next, antiseptics were removed, the universal neutralizing agent (Saline Peptone Water, Biocorp, Warsaw, Poland) was introduced for 5 min. After this time, the neutralizing agent was removed. Then, Live/Dead dye was introduced as presented in Material and Methods 3.3., the estimation of Fluorescence Intensity (measured by Mean Grey Value) and Biofilm-Covered Areas were performed as presented in Material and Methods 3.7.

\subsection{Statistical Analysis}


Calculations were performed using the GraphPad Prism version 7 software (GraphPad Co., San Diego, CA, USA). The normality of distribution was assessed by means of the D'Agostino-Pearson omnibus test. Because all values were non-normally distributed, the Kruskal-Wallis test with post-hoc Dunnett analysis were applied. The results of statistical analyses were considered significant if they produced $p$-values $<0.05$.

\section{Conclusions}

The staphylococcal biofilm in vitro displays highly differentiated structure, depended on conditions applied and intraspecies features. The preparation procedures (rinsing, especially) for microscopic analysis and further image processing significantly alter biofilm structure and have impact on analyses related with application of antiseptic agents. The SYTO-9 dye represents higher value for parametrical assessment of antiseptic impact on biofilm than propidium iodide. The developed and scrutinized in this research formula of Antiseptic's Biofilm Eradication, may be of high applicability in assessment of antiseptic activity against 3-dimensional biofilm structure.

Supplementary Materials: Table S1. Confluence [\%] of analyzed staphylococcal biofilms; Table 2S. The Fluorescence Intensity of live and dead (L, D, respectively) staphylococcal biofilms with regard to their location Figure 1S. The different types of Live/Dead cells' distribution in biofilm within single plate; Figure $2 \mathrm{~S}$. The representative size of staphylococcal ATCC 33591 strain in biofilm formed in vitro; Figure 3S. The staphylococcal biofilm seen with naked eye.

Author Contributions: Conceptualization, G.K., A.J., K.F.; methodology, G.K, A.J.; software, A.J.; validation, A.J., Y.Y; formal analysis, A.J, G.K; investigation, G.K., A.J., M.W., P.M., J.Cz., B.D., J.N., J.P., M.B., M.O.-W., G.C., B.K. ; resources, A.J., K.F.; data curation, G.C.; writing - original draft preparation, G.C, A.J.; writing-review and editing, A.J.; visualization, A.J.; supervision, A.J.; project administration, A.J.; funding acquisition, K.F.,A.J. All authors have read and agreed to the published version of the manuscript.

Funding: This research was funded by National Science Center (Grant No. 2017/27/B/NZ6/02103)

Institutional Review Board Statement: not applicable

Informed Consent Statement: not applicable

Data Availability Statement: the data presented in this study are available on reasonable request from the corresponding author

Acknowledgments: AJ would like to thank Howard Bloom (N.Y.C.) for teaching him to always ask: "What do I actually see here?"

Conflicts of Interest: The authors declare no conflict of interest

\section{References}


1. Junka, A. F.; Rakoczy, R.; Szymczyk, P.; Bartoszewicz, M.; Sedghizadeh, P. P.; Fijałkowski, K. Application of Rotating Magnetic Fields Increase the Activity of Antimicrobials Against Wound Biofilm Pathogens. Sci Rep 2018, 8, 1-12. https://doi.org/10.1038/s41598-017-185577.

2. $\quad$ Woroszyło, M.; Ciecholewska-Juśko, D.; Junka, A.; Wardach, M.; Chodaczek, G.; Dudek, B.; Fijałkowski, K. The Effect of Rotating Magnetic Field on Susceptibility Profile of Methicillin-Resistant Staphylococcus Aureus Strains Exposed to Activity of Different Groups of Antibiotics. Int. J. Mol. Sci. 2021, 22, 1-26. https://doi.org/10.3390/ijms222111551.

3. Krasowski, G.; Junka, A.; Paleczny, J.; Czajkowska, J.; Makomaska-Szaroszyk, E.; Chodaczek, G.; Majkowski, M.; Migdał, P.; Fijałkowski, K.; Kowalska-Krochmal, B.; Bartoszewicz, M. In Vitro Evaluation of Polihexanide, Octenidine and $\mathrm{NaClO} / \mathrm{HClO}-\mathrm{Based}$ Antiseptics against Biofilm Formed by Wound Pathogens. Membranes 2021, 11, 1-17. https://doi.org/10.3390/membranes11010062.

4. Wei, D.; Zhu, X. M.; Chen, Y. Y.; Li, X. Y.; Chen, Y. P.; Liu, H. Y.; Zhang, M. Chronic Wound Biofilms: Diagnosis and Therapeutic Strategies. Chin Med J (Engl) 2019, 132, $2737-$ 2744. https://doi.org/10.1097/CM9.0000000000000523.

5. Le, K. Y.; Dastgheyb, S.; Ho, T. v.; Otto, M. Molecular Determinants of Staphylococcal Biofilm Dispersal and Structuring. Front Cell Infect Microbiol 2014, 4, 1-7. https://doi.org/10.3389/fcimb.2014.00167.

6. Rodrigues, C. F.; Kaushik, K. S.; Light, C. Biofilms in Wounds: New Advances in Therapy and in Healing Management. Biomedicines 2021, 9, 1-2. https://doi.org/10.3390/biomedicines9020193.

7. Malone, M.; Bjarnsholt, T.; McBain, A. J.; James, G. A.; Stoodley, P.; Leaper, D.; Tachi, M.; Schultz, G.; Swanson, T.; Wolcott, R. D. The Prevalence of Biofilms in Chronic Wounds: A Systematic Review and Meta-Analysis of Published Data. J Wound Care 2017, 26, 20-25. https://doi.org/10.12968/jowc.2017.26.1.20.

8. Kramer, A.; Dissemond, J.; Kim, S.; Willy, C.; Mayer, D.; Papke, R.; Tuchmann, F.; Assadian, O. Consensus on Wound Antisepsis: Update 2018. Skin Pharmacol Physiol 2018, 31, 28-58. https://doi.org/10.1159/000481545.

9. Hübner, N. O.; Kramer, A. Review on the Efficacy, Safety and Clinical Applications of Polihexanide, a Modern Wound Antiseptic. Skin Pharmacol Physiol 2010, 23, 17-27. https://doi.org/10.1159/000318264.

10. Schneider, C. A.; Rasband, W. S.; Eliceiri, K. W. NIH Image to ImageJ: 25 Years of Image Analysis. Nat Methods 2012, 9, 671-675. https://doi.org/10.1038/nmeth.2089.

11. Abebe, G. M. The Role of Bacterial Biofilm in Antibiotic Resistance and Food Contamination. Int J Microbiol 2020, 2020, 1-10. https://doi.org/10.1155/2020/1705814.

12. Peter, H.; Ylla, I.; Gudasz, C.; Romanı, A. M.; Sabater, S.; Tranvik, L. J. Multifunctionality and Diversity in Bacterial Biofilms. PloS one 2011, 6, 1-8. https://doi.org/10.1371/ journal.pone.0023225.

13. Bradshaw, D. J. Metabolic Responses in Biofilms. Microb Ecol Health Dis 1995, 8, 313-316. https://doi.org/10.3109/08910609509140112.

14. Yeor-Davidi, E.; Zverzhinetsky, M.; Krivitsky, V.; Patolsky, F. Real-Time Monitoring of Bacterial Biofilms Metabolic Activity by a Redox-Reactive Nanosensors Array. $J$ Nanobiotechnology 2020, 18, 1-11. https://doi.org/10.1186/s12951-020-00637-y.

15. Costerton, W. J.; Cheng, K.-J.; Geesey, G. G.; Ladd, T. I.; Nickel, C. J.; Dasgupta, M.; Marrie, T. J. Bacterial Biofilms in Nature and Disease. Ann. Rev. Microbiol. 1987, 41, 435464. https://doi.org/10.1146/annurev.mi.41.100187.002251.

16. Wang, S. S.; Han, Y. H.; Chen, J. L.; Zhang, D. C.; Shi, X. X.; Ye, Y. X.; Chen, D. L.; Li, M. Insights into Bacterial Cellulose Biosynthesis from Different Carbon Sources and the 
Associated Biochemical Transformation Pathways in Komagataeibacter Sp. W1. Polymers 2018, 10, 1-20. https://doi.org/10.3390/polym10090963.

17. Hung, C.; Zhou, Y.; Pinkner, J. S.; Dodson, K. W.; Crowley, J. R.; Heuser, J.; Chapman, M. R.; Hadjifrangiskou, M.; Henderson, J. P.; Hultgren, S. J. Escherichia Coli Biofilms Have an Organized and Complex Extracellular Matrix Structure. MBio. 2013, 4, 1-10. https://doi.org/10.1128/mBio.00645-13.

18. Clinton, A.; Carter, T. Chronic Wound Biofilms: Pathogenesis and Potential Therapies. Lab Medicine 2015, 46, 277-284. https://doi.org/10.1309/LMBNSWKUI4JPN7SO.

19. Berlanga, M.; Guerrero, R. Living Together in Biofilms: The Microbial Cell Factory and Its Biotechnological Implications. Microb Cell Fact 2016, 15, 1-11. https://doi.org/10.1186/s12934-016-0569-5.

20. Otto, M. Staphylococcal Biofilms. In Bacterial Biofilms. Current Topics in Microbiology and Immunology; Romeo, T., Ed.; Springer: Berlin, Heidelberg, 2008; Vol. 322, pp 207-228. https://doi.org/10.1007/978-3-540-75418-3_10.

21. Merino, N.; Toledo-Arana, A.; Vergara-Irigaray, M.; Valle, J.; Solano, C.; Calvo, E.; Lopez, J. A.; Foster, T. J.; Penadés, J. R.; Lasa, I. Protein A-Mediated Multicellular Behavior in Staphylococcus Aureus. J Bacteriol 2009, 191, 832-843. https://doi.org/10.1128/JB.0122208 .

22. Kong, K. F.; Vuong, C.; Otto, M. Staphylococcus Quorum Sensing in Biofilm Formation and $\begin{array}{lllll}\text { Infection. Int } J \text { Med } & \text { Microbiol 2006, 296, 133-139. }\end{array}$ https://doi.org/10.1016/j.ijmm.2006.01.042.

23. Sharma, D.; Misba, L.; Khan, A. U. Antibiotics versus Biofilm: An Emerging Battleground in Microbial Communities. Antimicrob Resist Infect Control 2019, 8, 1-10. https://doi.org/10.1186/s13756-019-0533-3.

24. Davies, D. Understanding Biofilm Resistance to Antibacterial Agents. Nat. Rev. Drug Discov 2003, 2, 114-122. https://doi.org/10.1038/nrd1008.

25. Williams, D. L.; Bloebaum, R. D. Observing the Biofilm Matrix of Staphylococcus Epidermidis ATCC 35984 Grown Using the CDC Biofilm Reactor. Microsc Microanal 2010, 16, 143-152. https://doi.org/10.1017/S143192760999136X.

26. Flemming, H. C.; Wingender, J. The Biofilm Matrix. Nat. Rev. Microbiol. 2010, 8, 623-633. https://doi.org/10.1038/nrmicro2415.

27. Nguyen, H.; Ybarra, A.; Başağaoğlu, H.; Shindell, O. Biofilm Viscoelasticity and Nutrient Source Location Control Biofilm Growth Rate, Migration Rate, and Morphology in Shear Flow. Sci Rep 2021, 11, 1-17. https://doi.org/10.1038/s41598-021-95542-1.

28. Narla, A. v.; Borenstein, D. B.; Wingreen, N. S. A Biophysical Limit for Quorum Sensing in Biofilms. Proc Natl Acad Sci $U$ S A 2021, 118, 1-6. https://doi.org/10.1073/pnas.2022818118.

29. Dydak, K.; Junka, A.; Dydak, A.; Brożyna, M.; Paleczny, J.; Fijalkowski, K.; Kubielas, G.; Aniołek, O.; Bartoszewicz, M. In Vitro Efficacy of Bacterial Cellulose Dressings Chemisorbed with Antiseptics against Biofilm Formed by Pathogens Isolated from Chronic Wounds. Int. J. Mol. Sci. 2021, 22, 1-43. https://doi.org/10.3390/ijms22083996.

30. EN 13727: Chemical disinfectants and antiseptics - Quantitative suspension test for the evaluation of bactericidal activity in the medical area https://www.situbiosciences.com/product/en-13727-chemical-disinfectants-and-antisepticsquantitative-suspension-test-for-the-evaluation-of-bactericidal-activity-in-the-medical-area/ (accessed $2021-11-04)$.

31. Geraghty, R. J.; Capes-Davis, A.; Davis, J. M.; Downward, J.; Freshney, R. I.; Knezevic, I.; Lovell-Badge, R.; Masters, J. R. W.; Meredith, J.; Stacey, G. N.; Thraves, P.; Vias, M. Guidelines for the Use of Cell Lines in Biomedical Research. Br J Cancer 2014, 111, 10211046. https://doi.org/10.1038/bjc.2014.166. 
32. Mah, T. F. C.; O’Toole, G. A. Mechanisms of Biofilm Resistance to Antimicrobial Agents. Trends Microbiol 2001, 9, 34-39. https://doi.org/10.1016/S0966-842X(00)01913-2.

33. Monteiro, J. M.; Fernandes, P. B.; Vaz, F.; Pereira, A. R.; Tavares, A. C.; Ferreira, M. T.; Pereira, P. M.; Veiga, H.; Kuru, E.; Vannieuwenhze, M. S.; Brun, Y. v.; Filipe, S. R.; Pinho, M. G. Cell Shape Dynamics during the Staphylococcal Cell Cycle. Nat Commun 2015, 6, 112. https://doi.org/10.1038/ncomms9055.

34. Yanoff, M.; Duker, J. S. Ophthalmology 3rd Edition; Yanoff, M., Duker, J. S., Eds.; Elsevier, MOSBY: China, 2009.

35. Viljoen, A.; Mignolet, J.; Viela, F.; Mathelié-Guinlet, M.; Dufrêne, Y. F. How Microbes Use Force To Control Adhesion. J Bacteriol 2020, 202, 1-10. https://doi.org/10.1128/JB .0012520.

36. des Roches, S.; Post, D. M.; Turley, N. E.; Bailey, J. K.; Hendry, A. P.; Kinnison, M. T.; Schweitzer, J. A.; Palkovacs, E. P. The Ecological Importance of Intraspecific Variation. Nature Ecology and Evolution 2018, 2, 57-64. https://doi.org/10.1038/s41559-017-0402-5.

37. Latka, A.; Drulis-Kawa, Z. Advantages and Limitations of Microtiter Biofilm Assays in the Model of Antibiofilm Activity of Klebsiella Phage KP34 and Its Depolymerase. Sci Rep 2020, 10, 1-12. https://doi.org/10.1038/s41598-020-77198-5.

38. Merritt, J. H.; Kadouri, D. E.; O’Toole, G. A. Growing and Analyzing Static Biofilms. Curr $\begin{array}{llllll}\text { Protoc } & \text { Microbiol. } & \text { 2005, } & \text { Chapter } & 1, & 1-29 .\end{array}$ https://doi.org/10.1002/9780471729259.mc01b01s00.

39. Kramer, A.; Assadian, O.; Muller, G.; Reichwagen, S.; Widulla, H.; Heldt, P.; Nurnberg, W. Octenidine, Chlorhexidine, Iodine and Iodophores; Thieme, G., Ed.; Stuttgart, New York, Germany, USA, 2008.

40. ISO 10993-5:2009(en), Biological evaluation of medical devices - Part 5: Tests for in vitro cytotoxicity https://www.iso.org/obp/ui/\#iso:std:iso:10993:-5:ed-3:v1:en (accessed 2021 -11 04).

41. Pasquaroli, S.; Zandri, G.; Vignaroli, C.; Vuotto, C.; Donelli, G.; Biavasco, F. Antibiotic Pressure Can Induce the Viable but Non-Culturable State in Staphylococcus Aureus Growing in Biofilms. $J$ Antimicrob Chemother 2013, 68, 1812-1817. https://doi.org/10.1093/jac/dkt086.

42. Gottrup, F.; Apelqvist, J.; Bjansholt, T.; Cooper, R.; Moore, Z.; Peters, E. J. G.; Probst, S. EWMA Document: Antimicrobials and Non-Healing Wounds Evidence, Controversies and Suggestions. J Wound Care 2013, 22, S1-89. https://doi.org/10.12968/jowc.2013.22.Sup5.S1.

43. Müller, G.; Kramer, A. Biocompatibility Index of Antiseptic Agents by Parallel Assessment of Antimicrobial Activity and Cellular Cytotoxicity. J Antimicrob Chemother 2008, 61, 12811287. https://doi.org/10.1093/jac/dkn125.

44. Severing, A. L.; Rembe, J. D.; Koester, V.; Stuermer, E. K. Safety and Efficacy Profiles of Different Commercial Sodium Hypochlorite/Hypochlorous Acid Solutions ( $\mathrm{NaClO} / \mathrm{HClO}$ ): Antimicrobial Efficacy, Cytotoxic Impact and Physicochemical Parameters in Vitro. $J$ Antimicrob Chemother 2019, 74, 365-372. https://doi.org/10.1093/jac/dky432.

45. Zhang, M.; Zhang, J.; Wang, Y.; Wang, J.; Achimovich, A. M.; Acton, S. T.; Gahlmann, A. Non-Invasive Single-Cell Morphometry in Living Bacterial Biofilms. Nat Commun 2020, 11, 1-13. https://doi.org/10.1038/s41467-020-19866-8.

46. Paleczny, J.; Junka, A.; Brożyna, M.; Dydak, K.; Oleksy-Wawrzyniak, M.; CiecholewskaJuśko, D.; Dziedzic, E.; Bartoszewicz, M. The High Impact of Staphylococcus Aureus Biofilm Culture Medium on In Vitro Outcomes of Antimicrobial Activity of Wound Antiseptics and Antibiotic. Pathogens 2021, 10, 1-26. https://doi.org/10.3390/pathogens10111385. 
bioRxiv preprint doi: https://doi.org/10.1101/2021.11.30.470646; this version posted November 30, 2021. The copyright holder for this preprint (which was not certified by peer review) is the author/funder, who has granted bioRxiv a license to display the preprint in perpetuity. It is made available under aCC-BY-NC-ND 4.0 International license.

47. Bogino, P. C.; Oliva, M. de las M.; Sorroche, F. G.; Giordano, W. The Role of Bacterial Biofilms and Surface Components in Plant-Bacterial Associations. Int. J. Mol. Sci. 2013, 14, 15838-15859. https://doi.org/10.3390/ijms 140815838. 